\title{
The Kinetics and Thermodynamics of the Reaction of Solid-State Fully Reduced Membrane-Bound Cytochrome Oxidase with Carbon Monoxide as Studied by Dual-Wavelength Multichannel Spectroscopy and Flash Photolysis
}

\author{
By *G. MARIUS CLORE and EDWIN M. CHANCE \\ Department of Biochemistry, University College London, Gower Street, London WC1E 6BT, U.K.
}

(Received 23 November 1977)

\begin{abstract}
1. The results of non-linear optimization studies on the mechanism of reaction of solidstate fully reduced membrane-bound cytochrome oxidase with CO over the 178-203 K range are presented. The analysis is carried out on data obtained by dual-wavelength multichannel spectroscopy at three wavelength pairs $(444-463 \mathrm{~nm}, 590-630 \mathrm{~nm}$ and 608-630 nm), which yield three distinct progress curves. The only model that satisfies the triple requirement of a standard deviation within the standard error of the data, a random distribution of residuals and good determination of the optimized parameters is a twospecies sequential mechanism: flash photolysis yields unliganded cytochrome oxidase and free $\mathrm{CO}$, which then recombine to form species $I_{c} ; I_{c}$ is then converted into species $\mathrm{II}_{\mathrm{c}}$, which is identical with the cytochrome oxidase-CO complex existing before flash photolysis. All the thermodynamic parameters describing this model are calculated. 2. On the basis of the data obtained from this paper, together with data from potentiometric studies, magnetic susceptibility measurements and i.r. spectroscopy, the chemical identity of the species is suggested.
\end{abstract}

Cytochrome oxidase (EC 1.9.3.1), the terminal oxidase in the respiratory chain of all higher organisms, has been the focus of considerable interest owing to its central role in biological oxidation. In two previous papers (Clore \& Chance, 1978a,b) we analysed the kinetics and chemistry of the elementary steps of the reaction of fully reduced and ferricyanidepretreated mixed-valence-state membrane-bound cytochrome oxidase with oxygen by means of lowtemperature dual-wavelength multichannel spectroscopy and sophisticated non-linear stiff integration and optimization techniques to evaluate the experimental data quantitatively. In the present study, the kinetics and thermodynamics of $\mathrm{CO}$ binding to fully reduced membrane-bound cytochrome oxidase have been investigated in the solid state over the temperature range $178-203 \mathrm{~K}$ by a similar experimental and mathematical approach.

The reaction of $\mathrm{CO}$ with fully reduced cytochrome oxidase differs from that with $\mathrm{O}_{2}$ in two important respects: it is considerably slower and does not involve electron transfer (Chance et al., 1975c). Thus the reaction with $\mathrm{CO}$ affords one the opportunity to

Abbreviations used: R.S.Q., residual sum squares; S.D. In, standard deviation of the natural logarithm of a parameter; $N_{i}$, percentage absorbance change at the $i$ th wavelength.

* To whom correspondence should be addressed. study the mechanistic details of ligand binding in the absence of other concomitant processes. The temperature range $203-178 \mathrm{~K}$ was chosen for the following reasons. At these temperatures the system exists in the solid state in which exchange of $\mathrm{CO}$ between the active site and the solvent is not observed (Austin et al., 1975; Sharrock \& Yonetani, 1976), thus considerably simplifying the system under consideration. Furthermore, at higher temperatures, the time resolution of the multichannel spectrophotometer is not adequate; at lower temperatures, quantum mechanical tunnelling may occur (Austin et al., 1975; Goldanskii, 1976; Alberding et al., 1976), further complicating the system.

The present study differs from previous studies on the kinetics of $\mathrm{CO}$ binding to myoglobin (Austin et al., 1975), protohaem (Alberding et al., 1976) and soluble cytochrome oxidase (Sharrock \& Yonetani, 1976) in the following three very important respects.

(a) The reaction is monitored simultaneously at three wavelength pairs $(444-463 \mathrm{~nm}, 590-630 \mathrm{~nm}$ and $608-630 \mathrm{~nm}$ ) as opposed to a single wavelength pair. We demonstrate that these three wavelength pairs yield three distinct progress curves, indicating the existence of three or more spectroscopically distinct optical species. Hence the assumption of only two spectroscopically distinct optical species, bound and unbound, made by the above authors is not valid in 
the membrane-bound cytochrome oxidase-CO system. Consequently, the relative extinction coefficients, at the three wavelength pairs of any intermediates formed have to be determined by optimization. It should also be noted that the existence of different progress curves at different wavelengths not only yields more information as to the nature of the species, but also imposes much stricter constraints on the models developed.

(b) The data are fitted by optimizing the coefficients of the differential equations representing a particular kinetic model and not by optimizing the coefficients of a series of power law equations which are only approximations of the true mathematics of the model. Furthermore, instead of fitting the data at each temperature individually, we fit all the data at all the temperatures simultaneously by optimizing the rate constants at a reference temperature and the corresponding energies of activation.

(c) Our choice of model is based on a rigorous quantitative framework which requires that the model satisfies the three following criteria: a standard deviation within the standard error of the data, a random distribution of residuals and good determination of the optimized parameters (Clore \& Chance, $1978 a, b)$.

\section{Experimental}

\section{Biochemical methods}

Bovine heart mitochondria (Low \& Vallin, 1963) are suspended at $298 \mathrm{~K}$ in a medium containing $0.1 \mathrm{M}$-mannitol, 50 mM-sodium phosphate buffer, pH7.2, and $5 \mathrm{~mm}$-succinate and left for $10 \mathrm{~min}$ (i.e. until all the $\mathrm{O}_{2}$ in the preparation is exhausted). [Note that no significant changes in $\mathrm{pH}$ occur on lowering the temperature to as low as $143 \mathrm{~K}$ owing to the large buffering capacity of the high concentration of protein in the mitochondrial preparation (Clore \& Chance, 1978a).] The system is then cooled to $273 \mathrm{~K}$ and $100 \% \mathrm{CO}$ at $10^{5} \mathrm{~Pa}(1 \mathrm{~atm})$ is bubbled in for $10 \mathrm{~min}$. Ethylene glycol is then added (final concn. $30 \%, \mathrm{v} / \mathrm{v})$ and the preparation resaturated with $100 \% \mathrm{CO}$ at $10^{5} \mathrm{~Pa}(1 \mathrm{~atm})$ for a further $20 \mathrm{~min}$ in order to ensure full anaerobiosis and $\mathrm{CO}$ saturation. The concentration of COin the CO-saturated preparation is $1.2 \mathrm{~mm}$. The final concentration of mitochondria is $21 \mathrm{mg} / \mathrm{ml}$, which contains $7 \mu \mathrm{M}$-cytochrome oxidase (calculated from $\varepsilon_{\text {red.-ox. }}^{605}=24.0 \mathrm{~mm}^{-1}$. $\mathrm{cm}^{-1}$, Van Gelder, 1963). The preparation is then stored in an air-tight syringe at $252 \mathrm{~K}$ until used.

Reduced CO-saturated preparation $(1 \mathrm{ml})$ is injected into a cuvette with a $2 \mathrm{~mm}$ light-path precooled in liquid $\mathbf{N}_{2}$ in order to ensure uniform freezing. The cuvette is then transferred to the Dewar flask of the spectrophotometer through which is flowing thermoregulated $\mathrm{N}_{2}$ of the desired temperature. A thermocouple of gold/cobalt alloy and copper inside the cuvette is used for temperature measurements.

The reaction is activated by a $200 \mathrm{~J}$ xenon flash lamp that has a pulse width of $1 \mathrm{~ms}$. The same sample is used for all measurements and three recordings are made at each temperature. Between each recording the sample is warmed to $223 \mathrm{~K}$, a temperature at which all the CO molecules rebind so that a uniform initial state is established.

\section{Biophysical techniques}

The recombination of $\mathrm{CO}$ with cytochrome oxidase after flash photolysis is monitored by two timesharing Johnson Research Foundation multichannel dual-wavelength spectrophotometers (Chance et al., $1975 a, b)$, one affording wavelengths appropriate to haem kinetics in the region of the $\alpha$-band and the other in the Soret region. The wavelengths of light are isolated by filters of appropriate spectral intervals and are interlaced, one with another, at $8 \mathrm{~ms}$ intervals by synchronized $60 \mathrm{~Hz}$ rotating discs. The measuring beam was provided by a tungsten iodide lamp; the intensity was not sufficient to perturb the measured kinetics. Transmitted light was monitored with a multi-alkali photomultiplier (EMI 9592b). Thus all the data at each temperature are monitored simultaneously by using a single xenon flash. The xenon flash is approx. $99 \%$ saturating and the residual is not dissociated (Chance et al., 1975c, 1978; Clore \& Chance, 1978a,b).

\section{Spectroscopic recordings and data digitization}

The kinetics were resolved with an amplifier rise time of approx. $0.1 \mathrm{~s}$ and recorded on strip charts until equilibrium was reached. The data, which were digitized by the method of Clore \& Chance (1978a), are shown in Fig. 1, where the percentage absorbance change at three wavelength pairs $(444-463 \mathrm{~nm}, 590$ $630 \mathrm{~nm}$ and $608-630 \mathrm{~nm}$ ) is plotted on a logarithmic time scale extending from $0.1 \mathrm{~s}$ to $10^{3} \mathrm{~s}$ at six temperatures ranging from 203 to $178 \mathrm{~K}$. Owing to the turbidity of the solutions used, the signal-to-noise ratio at times less than $0.1 \mathrm{~s}$ is too low to obtain meaningful data. The overall standard error of the data, given by the weighted means of the standard errors of the individual spectroscopic curves, is $2 \pm 0.36 \%$. \{ The fractional error in the estimation of the standard errors of the individual spectroscopic curves, assuming a Gaussian distribution, is given by $1 /\left(2 m_{i}-2\right)^{\frac{1}{2}}$, where $m_{i}$ is the number of time points for curve $i$. The fractional error in the estimation of the overall standard error of the data, given by the weighted mean of the fractional errors of the individual curves, $\sum\left[m_{i} /\left(2 m_{i}-2\right)^{\frac{1}{1}}\right] / \sum m_{i}$, is 0.18 . $\}$

\section{Numerical techniques}

The numerical results of non-linear optimizations were obtained with a computer program FAC- 
SIMILE (Curtis, 1976, 1977; Curtis \& Kirby, 1977; E. M. Chance et al., 1977), which uses a modified version of Gear's method (Gear, 1971; Chance \& Curtis, 1970; Curtis \& Chance, 1972; Curtis, 1978) for the numerical integration of large systems of simultaneous non-linear stiff ordinary differential equations and Powell's method of unconstrained nonlinear optimization (Powell, 1965, 1972).

We minimize the residual sum squares given by:

$$
\begin{aligned}
\text { R.S.Q. } & =\sum_{i}^{n} \sum_{j=1}^{m} R_{i j}{ }^{2} \\
& =\sum_{i}^{n} \sum_{j=1}^{m}\left\{\left[v_{i j}-\left(u_{i j} / s_{i}\right)\right] / \sigma_{i}\right\}^{2}
\end{aligned}
$$

where $j$ identifies the time point and $i$ the data curve, $R_{i j}$ are the residuals, $v_{i j}$ the observed values, $u_{i j}$ the corresponding calculated values, $s_{i}$ a scale factor and $\sigma_{i}$ the standard error for curve $i$. At the minimum R.S.Q. is equal to $\chi^{2}$. From the R.S.Q. we calculate the standard deviation, which unlike the R.S.Q. is independent of the number of experimental points:

$$
\text { S.D. }=\phi\left[\text { R.S.Q. } /(d-p]^{\frac{1}{2}}\right.
$$

where $d$ is the total number of experimental points, $p$ the number of optimized parameters and $\phi$ the overall standard error of the data given by:

$$
\phi=\sum \sigma_{i} r_{i} / \sum r_{i}
$$

where $r_{i}$ is the range of curve $i$.

A quantitative measure of how accurately an unknown parameter $P_{l}$ is determined by optimization is given by the standard deviation of the natural logarithm of $\boldsymbol{P}_{\boldsymbol{l}}$. Since rate constants and other parameters need to be varied over a large range of values, $\ln \left(P_{l}\right)$ is varied. When the minimum R.S.Q. is achieved, a sensitivity matrix, expressing the dependence of each residual $R_{i j}$ on each parameter $P_{l}$ being at the best parameter values, is determined by adding 0.2 to each $\ln \left(P_{l}\right)$ in turn and examining the effect on each $R_{i j}$. The normal matrix is then calculated from the sensitivity matrix and inverted to obtain the variance-co-variance matrix which refers to $\ln \left(P_{l}\right)$. The variance S.D. $\ln ^{2}$ of each $\ln \left(P_{l}\right)$ is derived from this matrix and used to convert it into a correlation matrix, whose component $r_{k l}$ is the correlation coefficient between $\ln \left(P_{k}\right)$ and $\ln \left(P_{l}\right)$. Because of the linearity of logarithms less than 0.2 , a parameter whose S.D.In lies below this value has a relative standard deviation of \pm S.D.1n, and is considered to have a well-determined minimum in multidimensional parameter space. For larger values of S.D. ${ }_{\text {In }}$, up to 1 in magnitude, the parameter value is determined to within a factor of order e $(\simeq 2.72)$, and so its order of magnitude is known. Significantly larger values of S.D.In show that the observations are inadequate to determine the parameter. The $5 \%$ and
95\% confidence limits $\boldsymbol{P}_{5, l}$ and $\boldsymbol{P}_{95 . l}$ are calculated from:

$$
\begin{aligned}
& P_{5, l}=P_{l} \exp (-1.645 \text { S.D.1n }) \\
& P_{95, l}=P_{l} \exp (1.645 \text { S.D.1n })
\end{aligned}
$$

and represent values which the 'true' value of $P_{1}$ would lie between with 5 and $95 \%$ probability respectively, on the assumption that $\ln \left(P_{l}\right)$ is normally distributed.

A measure of the distribution of the residuals for the overall fit is given by the mean absolute correlation index $(\bar{C})$ :

$$
\bar{C}=\frac{1}{n} \sum_{i=1}^{n}\left|\sum_{j=1}^{m} R_{i j} /\left(\sum_{j=1}^{m} R_{i j}{ }^{2}\right)^{\frac{1}{2}}\right|
$$

where $m$ is the number of time points for each curve and $n$ the number of curves. A value of $\bar{C}$ significantly greater than 1.0 (the expected root-mean-square value of $\bar{C}$ if the residuals for each curve were all independent random variables of zero mean and the same variance) indicates that the departures between calculated and observed values are systematic (Clore \& Chance, 1978a).

As in previous papers (Clore \& Chance, 1978a,b), we wish to emphasize that the choice of model in nonlinear optimization problems depends not only on obtaining a S.D. within the standard error of the data, but also on obtaining a random distribution of residuals and good determination of the optimized parameters. This triple requirement greatly decreases the number of models available and provides a rigorous quantitative framework on which to base one's choice of model. In fact in stiff non-linear problems it is usually the case that only a single model will satisfy this triple requirement. Thus, for a given set of data, although there may be many models with an S.D. within the standard error of the data, models with too many degrees of freedom will fail such an analysis because of under-determination and models with too few degrees of freedom will fail such an analysis as a result of the introduction of systematic errors in the distribution of residuals.

\section{Results and Discussion}

The difference spectrum of the fully reduced cytochrome oxidase-CO complex with respect to fully reduced cytochrome oxidase has a peak at $430 \mathrm{~nm}$ and a trough at $444 \mathrm{~nm}$ in the Soret region, a peak at $545 \mathrm{~nm}$ in the $\beta$-region, and a peak at $590 \mathrm{~nm}$ and a trough at $605-612 \mathrm{~nm}$ in the $\alpha$-region (Yonetani, 1963; Chance et al., 1975c). In each experiment we measure simultaneously the percentage absorbance change $\left(N_{i}\right)$ at three wavelength pairs: $444-463$, $590-630$ and $608-630 \mathrm{~nm}$ (the reference wavelengths, 463 and $630 \mathrm{~nm}$, are isosbestic points). At the low

Vol. 175 


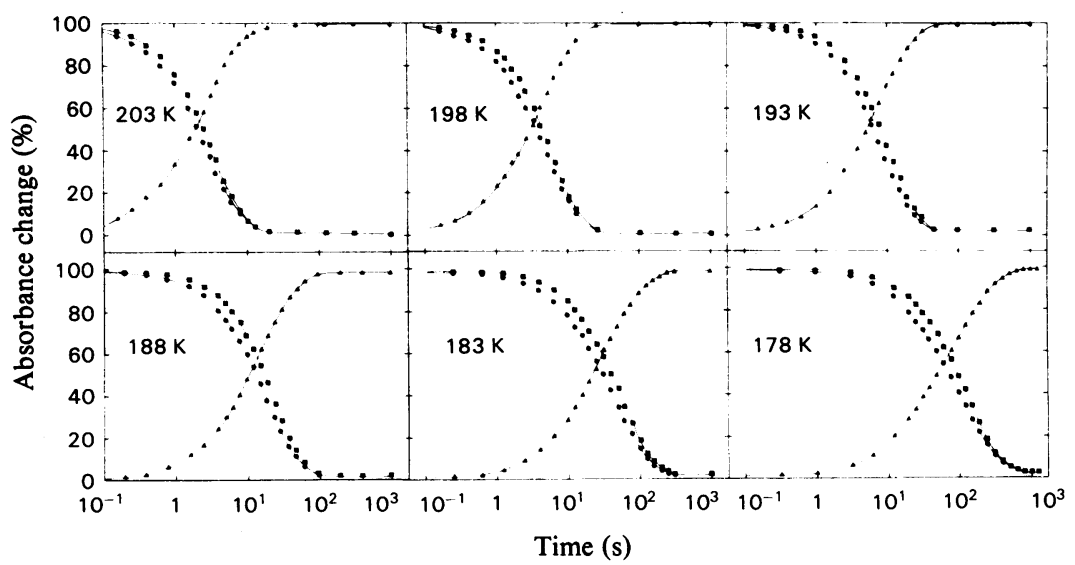

Fig. 1. Comparison of the observed kinetics of the reaction of fully reduced membrane-bound cytochrome oxidase with $C O$ with the computed kinetics obtained for model (1)

The experimental points are shown as: $\mathbf{}, 414-463 \mathrm{~nm} ; \bullet, 608-630 \mathrm{~nm} ; \Delta, 590-630 \mathrm{~nm}$. Theoretical curves are shown as solid lines. The experimental conditions are: bovine heart mitochondria, $21 \mathrm{mg} / \mathrm{ml}$ (containing $7 \mu \mathrm{M}$-cytochrome oxidase); $30 \%$ (v/v) ethylene glycol, $0.1 \mathrm{M}$-mannitol, $50 \mathrm{~mm}$-sodium phosphate buffer, pH 7.2, $5 \mathrm{~mm}$-succinate and $1.2 \mathrm{mM}-\mathrm{CO}$.

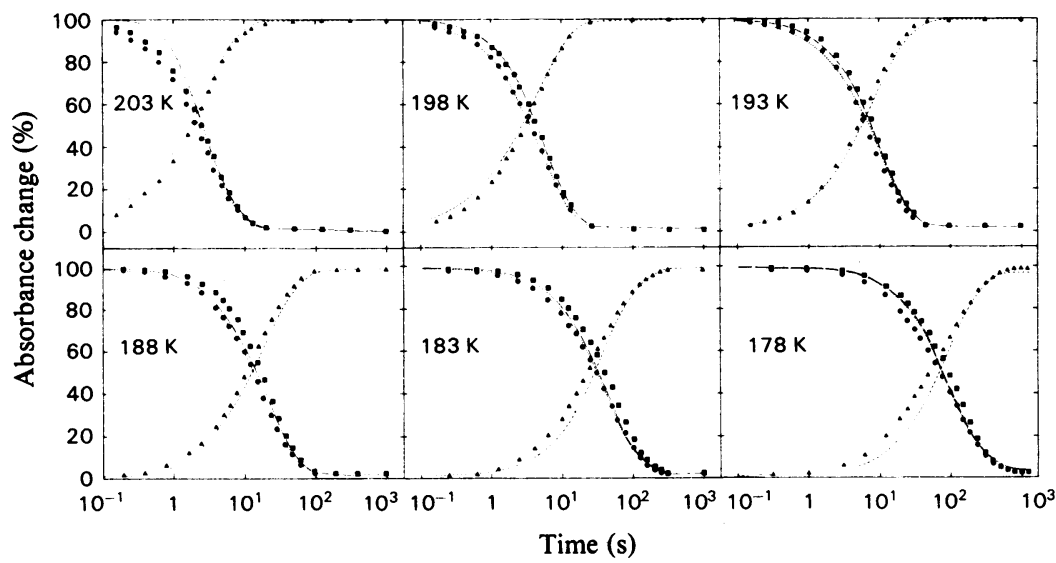

Fig. 2. Comparison of the observed kinetics of the reaction of fully reduced membrane-bound cytochrome oxidase with CO with the computed kinetics obtained for model (2)

The experimental points are shown as: $\square, 444-463 \mathrm{~nm} ; \bullet, 608-630 \mathrm{~nm} ; \Delta, 590-630 \mathrm{~nm}$. Theoretical curves are shown as:,$- 444-463 \mathrm{~nm} ; \cdots, 608-630 \mathrm{~nm} ;----, 590-630 \mathrm{~nm}$. The experimental conditions are the same as in Fig. 1.

temperatures used in this study, all the components of the respiratory chain, except for cytochrome oxidase, are inert (B. Chance et al., 1975c, 1977), so that the chosen wavelength pairs monitor solely the kinetics of the reaction of $\mathrm{CO}$ with fully reduced membranebound cytochrome oxidase.

In Figs. 1 and 2, the data plotted as $N_{i}$ versus log ( $t$ ) clearly demonstrate the different form of the progress curves at the three wavelength pairs. On the basis of Beer's law, it immediately follows that a minimum of three spectroscopically distinct optical species is present, two of which are monitored and must contribute in varying proportions at the three wavelength pairs. Thus the assumption of only two spectroscopically distinct optical species, bound and unbound, made by Austin et al. (1975), Alberding et al. (1976) and Sharrock \& Yonetani (1976) for the myoglobin- $\mathrm{CO}$, protohaem-CO and soluble cytochrome oxidase-CO systems is not valid for the membrane-bound cytochrome oxidase-CO system. 


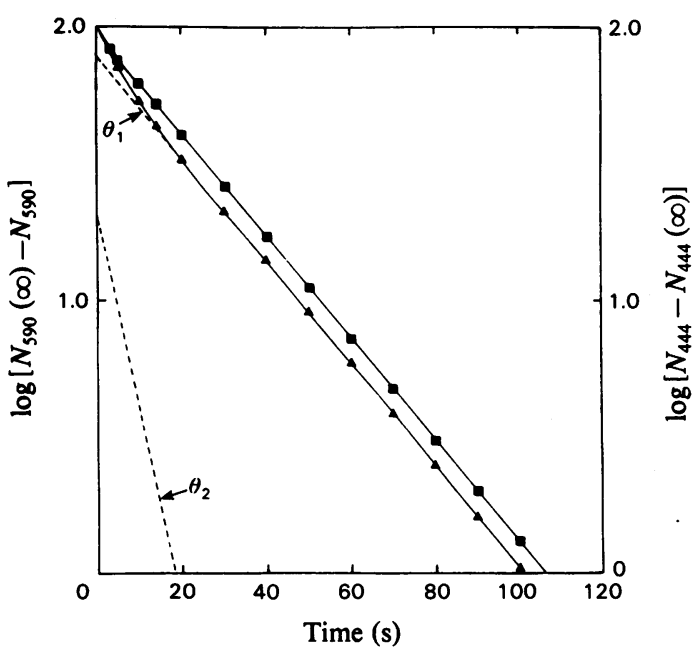

Fig. 3. Log-linear plot for the 590-630 nm and 444-463 nm traces at $188 \mathrm{~K}$

The experimental points are shown as: $\Delta, 590-630 \mathrm{~nm}$; $\square, 444-463 \mathrm{~nm}$. The broken lines are the two exponentials, $\theta_{1}$ and $\theta_{2}$, for the fast and slow processes, determined graphically from the $590-630 \mathrm{~nm}$ trace. The 590-630 nm trace is clearly biphasic with observed
It should be noted, however, that the above authors only monitored the kinetics of $\mathrm{CO}$ binding at a single wavelength pair so that the resolution of more than two spectroscopically distinct optical species is not possible on the basis of their data.

In Fig. 3, a plot of $\log \left[N_{590}(\infty)-N_{590}\right]$ versus time at $188 \mathrm{~K}$ is shown to yield a biphasic curve with observed rate constants of $0.17 \mathrm{~s}^{-1}$ and $0.044 \mathrm{~s}^{-1}$ for the fast and slow phases respectively. The difference in the intercepts $\left(\beta_{1}-\beta_{2}\right)$ on the $\log \left[N_{t}(\infty)-N_{t}\right]$ axis of the two exponentials making up such a plot will depend on the relative contributions of the two measured species at a given wavelength pair. When the two species contribute equally, $\left(\beta_{1}-\beta_{2}\right)$ will be at a maximum, and when only one species contributes, $\left(\beta_{1}-\beta_{2}\right)$ will be at a minimum (see Appendix I). If $\left(\beta_{1}-\beta_{2}\right)$ is much greater than 1.8 , the biphasic nature of such a plot will be obscured even if the ratio of the

rate constants of $0.17 \mathrm{~s}^{-1}$ and $0.044 \mathrm{~s}^{-1}$ for the fast and slow phases respectively. The deviation from linearity of the $444-463 \mathrm{~nm}$ trace, however, is very small and does not allow the graphical determination of the observed rate constant for the fast phase (for explanation of this phenomenon see the text).

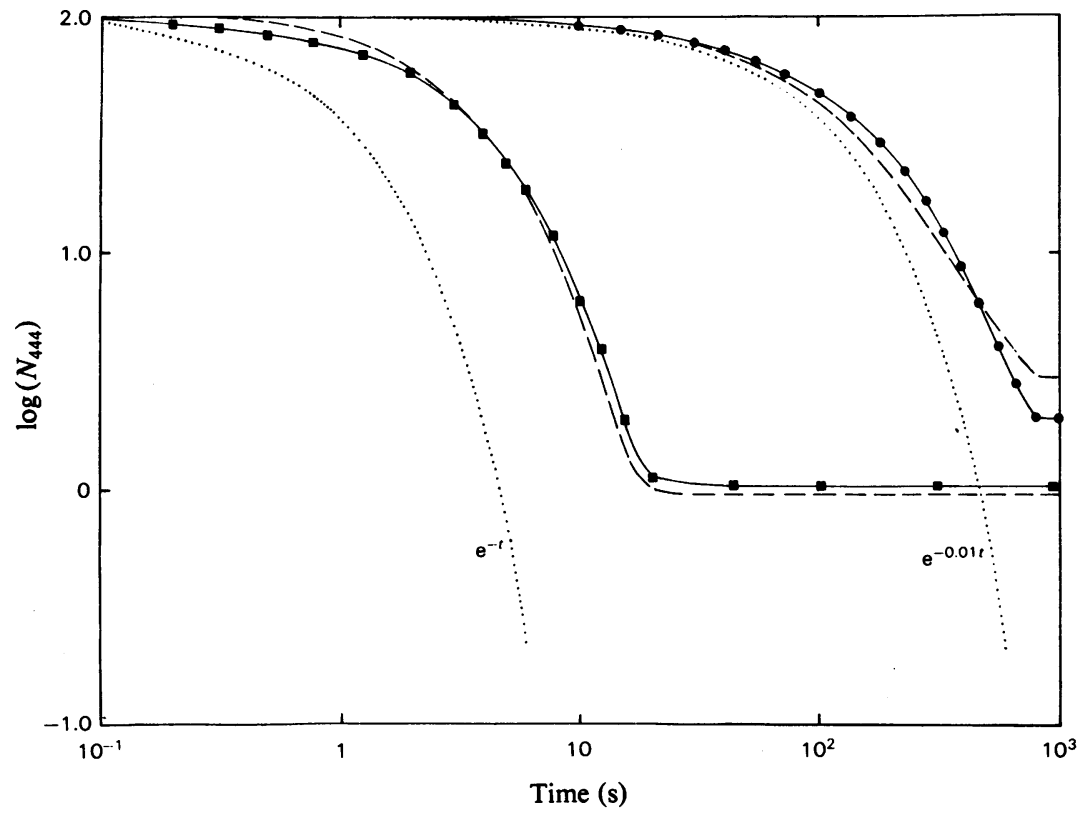

Fig. 4. Log-log plot of the experimental data at $444-463 \mathrm{~nm}$ at $178 \mathrm{~K}(\bullet)$ and $203 \mathrm{~K}(\boldsymbol{\square})$ together with the computed curves using model 1 ( $\longrightarrow$ ) and model 2 (----)

The curves for models (1) and (2) are calculated by using the optimized values of the parameters given in Tables 4 and 5 respectively. $\cdots$, Exponentials with relaxation times of $1 \mathrm{~s}$ and $0.01 \mathrm{~s}$ included for comparison. It can be seen that both experimental data and models deviate from single exponential behaviour, although for the experimental data and model (1) this deviation is not very pronounced.

Vol. 175 
observed rate constants for the fast and slow phases lies in the range 1-5. This is the case for a plot of log $\left[N_{444}-N_{444}(\infty)\right]$ versus time at $188 \mathrm{~K}$, which is nearly monophasic and in which the deviation from linearity is not sufficiently great to allow the graphical determination of the observed rate constant for the fast phase (Fig. 3). Further, the marked decrease in the biphasic character of the $444-463 \mathrm{~nm}$ trace relative to that of the $590-630 \mathrm{~nm}$ trace indicates that the ratio of the contributions of the two species being monitored at $444-463 \mathrm{~nm}$ is closer to unity than the ratio of the contributions of the two species being monitored at $590-630 \mathrm{~nm}$. Fig. 3 also demonstrates that the kinetics at $444-463$ and $590-630 \mathrm{~nm}$ at $188 \mathrm{~K}$ do not exhibit a lag phase. The same is true of the progress curves at the other temperatures.

We also note that the data in Fig. 1 extend over four orders of magnitude in time so that a plot of log $\left[N_{t}-N_{t}(\infty)\right]$ versus time will tend either to compress the fast or to eliminate the slow phases. In Fig. 4 we have therefore plotted $\log \left(N_{444}\right)$ versus $\log (t)$ at the two extreme temperatures of the data (178 and $203 \mathrm{~K})$. In a log-log plot, an exponential of the form $N(t)=$ $\exp (-k t)$ leads to the relation $\log N(t)=-0.434 \exp$ $2.30(\log k+\log t)$ so that the shape of such a function is independent of $k, k$ only determining the position along the $\log (t)$ axis. By referring to two exponentials $\left(\mathrm{e}^{-t}\right.$ and $\left.\mathrm{e}^{-0.01 t}\right)$ it can be clearly seen that the traces deviate from a single exponential. However, as in the soluble cytochrome oxidase-CO system (Sharrock \& Yonetani, 1976), but in contrast with the myoglobinCO (Austin et al., 1975) and protohaem-CO (Alberding et al., 1976) systems, the deviation from single exponential character in the initial stages of the traces (i.e. before the approach to equilibrium) is not very pronounced.

At the low temperatures used here, $\mathrm{CO}$ exchange between the 'pocket' of cytochrome oxidase containing the active site and the frozen solvent is negligible (owing to the marked temperature-dependence of diffusion-controlled processes). However, the observation of the pseudo-first-order reaction of both $\mathrm{O}_{2}$ (Chance et al., 1975c, 1978) and CO (Sharrock \& Yonetani, 1976) with cytochrome oxidase, together with the demonstration of gas exchanges in the active site at low temperatures (Hartzell \& Beinert, 1974), indicates that there is trapped within the active site a population of ligand molecules that is proportional to that of the solvent at the time of freezing. The linearity of the Arrhenius plots from very low temperatures towards the melting point of the solvent in the reaction with oxygen (Chance et al., 1975c) suggests that the constant of proportionality is 1 . We have therefore assumed, on the basis of the above evidence, that the concentration of $\mathrm{CO}$ in the 'pocket' of cytochrome oxidase (i.e. the initial CO concentration) is equal to that in the solvent, namely $1.2 \mathrm{~mm}$.
On the basis of the minimum three-species hypothesis, two models are proposed:

$$
\begin{aligned}
& \underbrace{\mathrm{E}+\mathrm{CO}_{\mathrm{p}}}_{\uparrow} \stackrel{k_{+1}}{\underset{k_{-1}}{\rightleftharpoons}} \mathrm{I}_{\mathrm{c}} \underset{k_{-1}}{\stackrel{k_{+1}}{\rightleftharpoons}} \mathrm{II}_{\mathrm{c}} \quad(\text { model 1) } \\
& \mathrm{E}+\mathrm{CO}_{\mathrm{p}} \underset{k-1}{\stackrel{k_{+1}}{\rightleftharpoons}} \mathrm{I}_{\mathrm{c}} \underset{\uparrow}{\stackrel{k_{+1}}{\rightleftharpoons}} \mathrm{II}_{\mathrm{c}} \quad(\text { model 2) }
\end{aligned}
$$

where $\uparrow$ indicates the species populated by flash photolysis of species $\mathrm{II}_{\mathrm{c}}$. The subscript $\mathrm{p}$ is used to label the free $\mathrm{CO}$ molecules present in the 'pocket'. [The subscript $c$ is used in the naming of species $I_{c}$ and $\mathrm{II}_{c}$ in order to distinguish them from those obtained in the reactions of fully reduced and mixedvalence-state cytochrome oxidase with $\mathrm{O}_{2}$ (Clore \& Chance, $1978 a, b)$.] In both models, species $\mathrm{II}_{\mathrm{c}}$ is the final $\mathrm{CO}$ complex and species $\mathrm{E}$ the fully reduced unliganded cytochrome oxidase. By the term unliganded we mean that in species E CO is not bound to any constituent within the 'pocket' (i.e. not only the haem iron, but also any amino acid residues in the 'pocket' to which $\mathrm{CO}$ may have access).

Flash photolysis of species $\mathrm{II}_{\mathrm{c}}$ results in the photodissociation of the bond between $\mathrm{CO}$ and haem iron. In model (1), photolysis of species $\mathrm{II}_{\mathrm{c}}$ yields species $\mathrm{E}$ and one molecule of free $\mathrm{CO}$ which is indistinguishable from the other free $\mathrm{CO}$ molecules in the 'pocket' (which are termed $\mathrm{CO}_{\mathrm{p}}$ ). In model (2) photolysis of species $\mathrm{II}_{c}$ yields species $\mathrm{I}_{\mathrm{c}}$ in which the photodissociated $\mathrm{CO}$ molecule occupies a region that is distinct from the 'pocket' and has a maximum occupancy of one $\mathrm{CO}$ molecule; this region can be visualized as a binding site that must capture the $\mathrm{CO}$ molecule before binding to haem iron can take place. Since flash photolysis produces more than $99 \%$ photodissociation of the haem iron-CO bond (Chance et al., 1975c; Austin et al., 1975; Alberding et al., 1976; Sharrock \& Yonetani, 1976; Clore \& Chance, $1978 a, b)$ the concentration of species $\mathrm{E}$ in model (1) and species $I_{c}$ in model (2) immediately after flash photolysis (i.e. at $t=0 \mathrm{~s}$ ) is $7 \mu \mathrm{M}$. In model $(1)$, species $\mathrm{E}$ then recombines with free $\mathrm{CO}\left(\mathrm{CO}_{\mathrm{p}}\right)$ to form an intermediate, species $I_{c}$, which is then converted into species $\mathrm{II}_{\mathrm{c}}$. It should be noted that, in model (1), CO could already be bound to haem iron in species $I_{c}$. In model (2), species $I_{c}$ can be converted directly into either species $\mathrm{II}_{c}$ or species $\mathrm{E}$ and one molecule of free $\mathrm{CO}\left(\mathrm{CO}_{\mathrm{p}}\right)$.

It should be noted that, with the sole difference that in our model two optical species (rather than one) are required to contribute to the measured wavelength pairs in order to account for the different mathematical forms of the progress curves at the three wavelength pairs monitored, the model of Alberding et al. (1976) for the protohaem-CO 
reaction is formally identical with model (2), and the model of Sharrock \& Yonetani (1976) for the soluble cytochrome oxidase-CO reaction differs from model (2) by the subdivision of the 'pocket' into two distinct regions with the same $\mathrm{CO}$ occupancy as the 'pocket'.

The contribution of each intermediate to each wavelength is represented by a relative extinction coefficient. The crude computed absorbance at the $i$ th wavelength, $W_{i}(t)$, in units of concentration, is given by:

$$
W_{i}(t)=\sum_{l} \varepsilon_{i}^{\prime}(l) F_{l}(t)
$$

where $F_{l}(t)$ is the concentration of the $l$ th intermediate at time $t$, and $\varepsilon_{i}^{\prime}(l)$ is the relative extinction coefficient of the $l$ th intermediate at the $i$ th wavelength. The $F_{l}(t)$ are obtained either by numerical integration [using Gear's (1971) method] or from the analytical solutions \{derived on the basis that $\left[\mathrm{CO}_{\mathrm{p}}\right] \gg([\mathrm{E}]+$ $\left.\left[\mathrm{I}_{\mathrm{c}}\right]+\left[\mathrm{II}_{\mathrm{c}}\right]\right)$ and given in Appendix $\left.\mathrm{I}\right\}$ of the following coupled simultaneous differential equations:

$$
\begin{aligned}
\frac{\mathrm{d}[\mathrm{E}]}{\mathrm{d} t} & =-k_{+1}[\mathrm{E}]\left[\mathrm{CO}_{\mathrm{p}}\right]+k_{-1}\left[\mathrm{I}_{\mathrm{c}}\right] \\
\frac{\mathrm{d}\left[\mathrm{CO}_{\mathrm{p}}\right]}{\mathrm{d} t} & =\frac{\mathrm{d}[\mathrm{E}]}{\mathrm{d} t} \\
\frac{\mathrm{d}\left[\mathrm{I}_{\mathrm{c}}\right]}{\mathrm{d} t} & =k_{+1}[\mathrm{E}]\left[\mathrm{CO}_{\mathrm{p}}\right]-\left[\mathrm{I}_{\mathrm{c}}\right]\left(k_{-1}+k_{+2}\right)+k_{+2}\left[\mathrm{II}_{\mathrm{c}}\right] \\
\frac{\mathrm{d}\left[\mathrm{II}_{\mathrm{c}}\right]}{\mathrm{d} t} & =k_{+2}\left[\mathrm{I}_{\mathrm{c}}\right]-k_{-2}\left[\mathrm{II}_{\mathrm{c}}\right]
\end{aligned}
$$

with conditions immediately after flash photolysis (i.e. at $t=0 \mathrm{~s}$ ) of :

$[\mathrm{E}]=7 \mu \mathrm{M}, \quad\left[\mathrm{CO}_{\mathrm{p}}\right]=1.2 \mathrm{mM}, \quad\left[\mathrm{I}_{\mathrm{c}}\right]=\left[\mathrm{II}_{\mathrm{c}}\right]=0$

for model (1) and of:

$$
\left[\mathrm{I}_{\mathrm{c}}\right]=7 \mu \mathrm{M}, \quad\left[\mathrm{CO}_{\mathrm{p}}\right]=1.2 \mathrm{mM}, \quad[\mathrm{E}]=\left[\mathrm{II}_{\mathrm{c}}\right]=0
$$

for model (2). [Note that, under the pseudo-first-order conditions of these experiments, the analytical solutions given in Appendix I are identical with those obtained by numerical integration (which do not require the assumption of pseudo-first-order conditions) within a relative error of approx. $10^{-3}$.]

Since all measurements on digitization are made with respect to the states before (i.e. species $\mathrm{II}_{c}$ ) and immediately after flash photolysis [i.e. E in model (1) and species $I_{c}$ in model (2)], it follows that only two out of the three optical species contribute to the traces at any one wavelength pair. Since flash photolysis yields a single species in both models, it follows that for the $444-463 \mathrm{~nm}$ and $608-630 \mathrm{~nm}$ traces, which are characterized by an increase in absorbance on flash photolysis followed by a decay back to the baseline, we can set $\varepsilon_{444}^{\prime}\left(\mathrm{II}_{\mathrm{c}}\right)$ and $\varepsilon_{608}^{\prime}\left(\mathrm{II}_{\mathrm{c}}\right)$ to zero in both models, $\varepsilon_{444}^{\prime}(\mathrm{E})$ and $\varepsilon_{608}^{\prime}(\mathrm{E})$ to 1.0 in model (1), and $\varepsilon_{444}^{\prime}\left(I_{c}\right)$ and $\varepsilon_{608}^{\prime}\left(I_{c}\right)$ to 1.0 in model (2). For the
590-630 nm traces, which are characterized by a decrease in absorbance on flash photolysis followed by a gradual increase in absorbance up to the baseline, we can set $\varepsilon_{590}^{\prime}\left(\mathrm{II}_{\mathrm{c}}\right)$ to 1.0 in both models, $\varepsilon_{590}^{\prime}(\mathrm{E})$ to zero in model (1), and $\varepsilon_{590}^{\prime}\left(I_{c}\right)$ to zero in model (2). Thus, for model (1):

$$
\begin{aligned}
& W_{444}=[\mathrm{E}] \varepsilon_{444}^{\prime}(\mathrm{E})+\left[\mathrm{I}_{\mathrm{c}}\right] \varepsilon_{444}^{\prime}\left(\mathrm{I}_{\mathrm{c}}\right) \\
& W_{608}=[\mathrm{E}] \varepsilon_{608}^{\prime}(\mathrm{E})+\left[\mathrm{I}_{\mathrm{c}}\right] \varepsilon_{608}^{\prime}\left(\mathrm{I}_{\mathrm{c}}\right) \\
& W_{590}=\left[\mathrm{I}_{\mathrm{c}}\right] \varepsilon_{520}^{\prime}\left(\mathrm{I}_{\mathrm{c}}\right)+\left[\mathrm{II} \mathrm{I}_{\mathrm{c}}\right] \varepsilon_{590}^{\prime}\left(\mathrm{II}_{\mathrm{c}}\right)
\end{aligned}
$$

and for model (2):

$$
\begin{aligned}
& W_{444}=[\mathrm{E}] \varepsilon_{444}^{\prime}(\mathrm{E})+\left[\mathrm{I}_{\mathrm{c}}\right] \varepsilon_{444}^{\prime}\left(\mathrm{I}_{\mathrm{c}}\right) \\
& W_{608}=[\mathrm{E}] \varepsilon_{608}^{\prime}(\mathrm{E})+\left[\mathrm{I}_{\mathrm{c}}\right] \varepsilon_{608}^{\prime}\left(\mathrm{I}_{\mathrm{c}}\right) \\
& W_{590}=[\mathrm{E}] \varepsilon_{590}^{\prime}(\mathrm{E})+\left[\mathrm{II}_{\mathrm{c}}\right] \varepsilon_{590}^{\prime}\left(\mathrm{II}_{\mathrm{c}}\right)
\end{aligned}
$$

In both models there are three unknown relative extinction coefficients: $\varepsilon_{444}^{\prime}\left(I_{c}\right), \varepsilon_{590}^{\prime}\left(I_{c}\right)$ and $\varepsilon_{608}^{\prime}\left(I_{c}\right)$ in model $(1) ; \varepsilon_{444}^{\prime}(\mathrm{E}), \varepsilon_{590}^{\prime}(\mathrm{E})$ and $\varepsilon_{608}^{\prime}(\mathrm{E})$ in model (2). [Note that knowing the value of $\Delta \varepsilon_{1 I_{\mathrm{c}} \mathrm{a}}(T)$ at a temperature $T$ where $i$ is the wavelength and $a$ the intermediate obtained on flash photolysis, the value of $\Delta \varepsilon_{I_{\mathrm{c}}-b}{ }^{l}(T)$, where $b$ is the other intermediate, is given by $\varepsilon_{i}^{\prime}(b) \cdot \Delta \varepsilon_{\mathrm{II}_{\mathrm{c}}-\mathrm{a}}(T)$.]

$W_{l}(t)$ is converted into a percentage absorbance change, $N_{t}(t)$, for comparison with the normalized data by the equation:

$$
N_{i}(t)=\frac{W_{i}(t)}{B} \times 100 \%
$$

where $B$ is the total concentration of cytochrome oxidase (i.e. free plus bound, $7 \mu \mathrm{M}$ ).

We assume that the temperature-dependence of the rate constants can be described by activatedcomplex theory (Bamford \& Tipper, 1969). This is reasonable, since quantum mechanical tunnelling only becomes significant in proteins at temperatures below 20K (Austin et al., 1975; Goldanskii, 1976). Thus the temperature-dependence of a rate constant $k$ is given by:

$$
k(T)=\kappa \frac{k_{\mathrm{B}} T}{h} Z \exp \left(-E_{\mathrm{A}}{ }^{\circ} / R T\right)
$$

where $k_{\mathrm{B}}$ is the Boltzmann constant, $h$ Planck's constant, $\boldsymbol{R}$ the gas constant, and $T$ the absolute temperature; $\kappa$ is the transmission coefficient; $Z$ is a partition function; $E_{\mathrm{A}}{ }^{0}$ is the activation energy at absolute zero (i.e. the difference in energy between the zero-point levels in the initial and activated states; at any other temperature, the observed activation energy is the difference between the average properties of the reactants and of the activated complex).

Except for the vibrational partition function, which is close to unity in most cases and does not depend very much on $T$, the other partition functions 
involve $T$ to a simple power $n$ so that the rate constant for a reaction can be expressed in the form:

$$
k(T)=\lambda T^{n} \exp \left(-E_{\mathrm{A}}{ }^{0} / R T\right)
$$

where $\lambda$ is a constant. Thus, by determining the value of a given rate constant, $k\left(T_{\mathrm{D}}\right)$ at a reference temperature, $T_{\mathrm{D}}$, and the value of the corresponding activation energy, $E_{\mathrm{A}}{ }^{\circ}$, by optimization, we calculate the value of $k\left(T_{i}\right)$ at a temperature $T_{i}$ by:

$$
k\left(T_{i}\right)=\frac{T_{l}^{n}}{T_{\mathrm{D}}{ }^{n}} k\left(T_{\mathrm{D}}\right) \exp \left[\frac{E_{\mathrm{A}}^{0}}{R}\left(\frac{1}{T_{\mathrm{D}}}-\frac{1}{T_{i}}\right)\right]
$$

The reference temperature used here is $188 \mathrm{~K}$. Classically, for a bimolecular reaction involving one mobile linear reactant (in this case $\mathrm{CO}$ ) and a reactant (cytochrome oxidase) and activated complex whose rotation is restricted (in this case by the frozen crystalline lattice), the value of $n$ is $-3 / 2$; for a unimolecular reaction involving a reactant and activated complex whose rotation is restricted, $n$ has

Table 1. Values of $\chi^{2}$, the overall standard deviation of the fit and the mean absolute correlation index $(\bar{C})$ for models (1) and (2)

$\bar{C}$ is a measure of the distribution of residuals. For $\bar{C} \leqslant 1$, the distribution of residuals is random; for $C \gg 1$ the departures between observed and calculated values are systematic. For values of $f>100$, where $f$ is the number of degrees of freedom, the confidence limits for $\chi^{2}$ are given by $\frac{1}{2}\left[(2 f-1)^{\frac{1}{2}}\left(1 \pm \zeta z_{\alpha / 2}\right)\right]^{2}$, where $z_{\alpha / 2}$ is the value of the standard normal variable at the $\alpha / 2$ confidence level and $\zeta$ is the fractional error in the estimation of the overall standard error of the data (in this case 0.18 ). The $99 \%$ confidence interval for $\chi^{2}$ at 289 degrees of freedom is $83.4-617$. The overall standard error of the data is $2 \pm 036 \%$ with a $99 \%$ confidence interval of $1.08-2.92 \%$.

Model (1) Model (2)

$$
\begin{aligned}
& \chi^{2} \text { for } 289 \text { degrees of freedom } \\
& \text { ( } 300 \text { data points and } 11 \\
& \text { optimized parameters) } \\
& \text { Overall s.D. }
\end{aligned}
$$$$
283
$$$$
\text { C }
$$

$\begin{array}{ll}283 & 998 \\ & \\ 1.98 \% & 3.72 \% \\ 1.02 \% & 1.58 \%\end{array}$

a value of 1 . However, modern treatments (Lin \& Eyring, 1972) indicate that the value of $n$ is strongly model-dependent (e.g. for a unimolecular reaction $n= \pm 1 / 2)$. Since the temperature range of these experiments (178-203 K) and the range for which the results are extrapolated $(140-240 \mathrm{~K})$ are relatively small, the temperature-dependence of the preexponential part of eqn. (14) is insignificant relative to the temperature-dependence of the exponential part (e.g. for $n=1, T_{240} / T_{\mathrm{D}}=1.28$ and $T_{140} / T_{\mathrm{D}}=$ $0.745)$; therefore, assuming temperature-independence of the pre-exponential part of eqn. (14) (i.e. setting $n=0$ ) appears to be a good compromise.

During optimization, all the progress curves were fitted together. All the following parameters were varied simultaneously in both models: the rate constants, $k_{+1}\left(T_{\mathrm{D}}\right), k_{-1}\left(T_{\mathrm{D}}\right), k_{+2}\left(T_{\mathrm{D}}\right)$ and $k_{-2}\left(T_{\mathrm{D}}\right)$; the corresponding activation energies: $E_{\mathrm{A}_{+1}}^{0}, E_{\mathrm{A}_{-1}}^{0}, E_{\mathrm{A}_{+2}}^{0}$ and $E_{\mathbf{A}_{-2}}^{0}$. In addition, the following relative extinction coefficients were varied simultaneously with the above parameters: in model $1, \varepsilon_{444}^{\prime}\left(I_{c}\right), \varepsilon_{608}^{\prime}\left(I_{c}\right)$ and $\varepsilon_{590}^{\prime}\left(\mathrm{I}_{c}\right)$ [these were varied relative to $\varepsilon_{444}^{\prime}(\mathrm{E}), \varepsilon_{608}^{\prime}(\mathrm{E})$ and $\varepsilon_{590}^{\prime}\left(\mathrm{II}_{\mathrm{c}}\right)$ respectively, which were set to 1.0]; in model 2, $\varepsilon_{444}^{\prime}(\mathrm{E}), \varepsilon_{608}^{\prime}(\mathrm{E})$ and $\varepsilon_{590}^{\prime}(\mathrm{E})$ [these were varied relative to $\varepsilon_{444}^{\prime}\left(\mathrm{I}_{c}\right), \varepsilon_{608}^{\prime}\left(\mathrm{I}_{c}\right)$ and $\varepsilon_{590}^{\prime}\left(\mathrm{II}_{c}\right)$ respectively, which were set to 1.0$]$.

The results of optimization are shown in Table 1, which gives the values of $\chi^{2}$, the overall S.D. of the fit and the mean absolute correlation index $(\bar{C})$ for both models. The correlation matrix of the optimized parameters is shown in Tables 2 and 3 for models (1) and (2) respectively. Tables 4 and 5 give the values, S.D. In and 5-95\% confidence limits of the optimized parameters for models (1) and (2) respectively. Model (1) satisfies all three statistical criteria of goodness of fit, namely an S.D. within the standard error of the data (i.e. S.D. $<2 \%$ ), a random distribution of residuals (i.e. $\bar{C} \approx 1.0$ ) and good determination of the optimized parameters. Model (2), however, fails on two counts: its S.D. is significantly greater than $2 \%$ and the distribution of residuals is

\begin{tabular}{|c|c|c|c|c|c|c|c|c|}
\hline & $k_{+1}\left(T_{D}\right)$ & $k_{-1}\left(T_{D}\right)$ & $k_{+2}\left(T_{D}\right)$ & $k_{-2}\left(T_{D}\right)$ & $E_{\mathrm{A}-1}^{0}$ & $E_{\mathbf{A}_{1}^{0}}^{0}$ & $E_{\mathrm{A}_{2}^{0}}^{0}$ & $E_{\mathrm{A}-2}^{0}$ \\
\hline $\begin{array}{l}k_{+1}\left(T_{D}\right) \\
k_{-1}\left(T_{D}\right)\end{array}$ & $\begin{array}{l}1.00 \\
0.0621\end{array}$ & 1.00 & & & & & & \\
\hline$k_{+2}\left(T_{\mathrm{D}}\right)$ & 0.0239 & 0.748 & 1.00 & & & & & \\
\hline$k_{-2}\left(T_{\mathrm{D}}\right)$ & 0.0877 & -0.0121 & 0.0284 & 1.00 & & & & \\
\hline$E_{\mathrm{A}_{1}}^{\mathrm{O}}$ & -0.303 & 0.132 & -0.0162 & 0.0901 & 1.00 & & & \\
\hline$E_{\mathrm{A}-1}^{0}$ & 0.0876 & -0.959 & -0.632 & -0.0012 & -0.123 & 1.00 & & \\
\hline$E_{\mathrm{A}_{2}^{0}}^{-1}$ & -0.388 & 0.654 & 0.398 & -0.270 & -0.182 & -0.647 & 1.00 & \\
\hline$E_{\mathrm{A}-2}$ & -0.165 & 0.393 & 0.155 & -0.231 & -0.193 & -0.458 & 0.588 & 1.00 \\
\hline
\end{tabular}
not random $(\bar{C} \gg 1.0)$.

The comparison of experimental traces and computed curves is shown in Figs. 1 and 2 for models (1)

Table 2. Correlation matrix relating the optimized rate constants and activation energies for model (1) The reference temperature, $T_{\mathrm{D}}$, is $188 \mathrm{~K}$. 
Table 3. Correlation matrix relating the optimized rate constants and activation energies for model (2) The reference temperature, $T_{\mathrm{D}}$, is $188 \mathrm{~K}$.

\begin{tabular}{|c|c|c|c|c|c|c|c|c|}
\hline & $k_{+1}\left(T_{D}\right)$ & $k_{-1}\left(T_{\mathrm{D}}\right)$ & $k_{+2}\left(T_{\mathrm{D}}\right)$ & $k_{-2}\left(T_{\mathrm{D}}\right)$ & $E_{\mathrm{A}_{1}^{0}}^{0}$ & $E_{\mathrm{A}-1}^{0}$ & $E_{\mathrm{A}_{2}^{0}}^{0}$ & $E_{\mathrm{A}-2}^{0}$ \\
\hline $\begin{array}{l}k_{+1}\left(T_{\mathrm{D}}\right) \\
k_{-1}\left(T_{\mathrm{D}}\right) \\
k_{+2}\left(T_{\mathrm{D}}\right) \\
k_{-2}\left(T_{\mathrm{D}}\right) \\
E_{\mathrm{A} 1}^{0} \\
E_{\mathrm{A}}^{0}-1 \\
E_{\mathrm{A}_{2}^{0}}^{0} \\
E_{\mathrm{A}-2}^{0}\end{array}$ & $\begin{array}{r}1.00 \\
0.896 \\
0.200 \\
0.366 \\
-0.734 \\
-0.594 \\
0.110 \\
-0.158\end{array}$ & $\begin{array}{c}1.00 \\
0.555 \\
0.117 \\
-0.679 \\
-0.688 \\
0.348 \\
-0.0382\end{array}$ & $\begin{array}{c}1.00 \\
-0.220 \\
-0.263 \\
-0.431 \\
0.896 \\
0.320\end{array}$ & $\begin{array}{c}1.0 \\
-0.439 \\
-0.274 \\
-0.330 \\
0.153\end{array}$ & $\begin{array}{c}1.00 \\
0.841 \\
-0.195 \\
-0.0749\end{array}$ & $\begin{array}{c}1.00 \\
-0.295 \\
-0.207\end{array}$ & $\begin{array}{l}1.00 \\
0.437\end{array}$ & 1.00 \\
\hline
\end{tabular}

Table 4. Values of the optimized parameters together with their S.D. In and confidence limits for model (1) The reference temperature, $T_{\mathrm{D}}$, is $188 \mathrm{~K}$.

\begin{tabular}{|c|c|c|c|c|c|}
\hline \multirow[b]{2}{*}{ Parameter } & \multirow[b]{2}{*}{ Dimensions } & \multirow{2}{*}{$\begin{array}{l}\text { Optimized } \\
\text { value }\end{array}$} & \multirow[b]{2}{*}{ S.D.1n } & \multicolumn{2}{|c|}{ Confidence limits } \\
\hline & & & & $5 \%$ & $95 \%$ \\
\hline$k_{+1}\left(T_{\mathrm{D}}\right)$ & $M^{-1} \cdot \mathrm{s}^{-1}$ & 132 & 0.103 & 111 & 156 \\
\hline$k_{-1}\left(T_{\mathrm{D}}\right)$ & $\mathrm{s}^{-1}$ & 0.00345 & 0.493 & 0.00153 & 0.00776 \\
\hline$k_{+2}\left(T_{\mathrm{D}}\right)$ & $s^{-1}$ & 0.0441 & 0.0410 & 0.0413 & 0.0472 \\
\hline$k_{-2}\left(T_{\mathrm{D}}\right)$ & $\mathrm{s}^{-1}$ & 0.000946 & 0.210 & 0.000670 & 0.00134 \\
\hline$E_{\mathrm{A} 1}^{0}$ & $\mathrm{~kJ} \cdot \mathrm{mol}^{-1}$ & 40.9 & 0.0224 & 39.4 & 42.4 \\
\hline$E_{\mathrm{A}-1}^{1}$ & $\mathrm{~kJ} \cdot \mathrm{mol}^{-1}$ & 110 & 0.0463 & 102 & 118 \\
\hline$E_{A_{2}^{0}}^{0-1}$ & $\mathrm{~kJ} \cdot \mathrm{mol}^{-1}$ & 51.9 & 0.0255 & 49.7 & 54.1 \\
\hline$E_{\mathrm{A}-2}^{\mathrm{O}}$ & $\mathrm{kJ} \cdot \mathrm{mol}^{-1}$ & 34.5 & 0.216 & 24.2 & 49.2 \\
\hline $\begin{array}{l}\text { A-2 } \\
\varepsilon_{444}^{\prime}(\mathrm{I})^{*}\end{array}$ & & 0.780 & 0.0358 & 0.735 & 0.827 \\
\hline$\varepsilon_{608}(\mathrm{I})^{*}$ & & 0.639 & 0.0472 & 0.591 & 0.690 \\
\hline$\varepsilon^{\prime}$ & & 0.483 & 0.0670 & 0.432 & 0.539 \\
\hline
\end{tabular}

${ }^{*} \varepsilon_{444}^{\prime}\left(\mathrm{I}_{\mathrm{c}}\right), \varepsilon_{608}^{\prime}\left(\mathrm{I}_{\mathrm{c}}\right)$ and $\varepsilon_{590}^{\prime}\left(\mathrm{I}_{\mathrm{c}}\right)$ are varied relative to $\varepsilon_{444}^{\prime}(\mathrm{E}), \varepsilon_{608}^{\prime}(\mathrm{E})$ and $\varepsilon_{590}^{\prime}\left(\mathrm{II}_{\mathrm{c}}\right)$ respectively, which are set to 1.0.

Table 5. Values of the optimized parameters together with their S.D.In and confidence limits for model (2) The reference temperature, $T_{\mathrm{D}}$, is $188 \mathrm{~K}$.

\begin{tabular}{|c|c|c|c|c|c|}
\hline \multirow[b]{2}{*}{ Parameter } & \multirow[b]{2}{*}{ Dimensions } & \multirow{2}{*}{$\begin{array}{l}\text { Optimized } \\
\text { value }\end{array}$} & \multirow[b]{2}{*}{ S.D. $1 \mathrm{n}$} & \\
\hline & & & & $5 \%$ & $95 \%$ \\
\hline$k_{+1}\left(T_{\mathrm{D}}\right)$ & $M^{-1} \cdot s^{-1}$ & 712 & 0.493 & 31.6 & 160 \\
\hline$k_{-1}\left(T_{\mathrm{D}}\right)$ & $\mathrm{s}^{-1}$ & 0.0221 & 0.509 & 0.00956 & 0.0509 \\
\hline$k_{+2}\left(T_{\mathrm{D}}\right)$ & $\mathrm{s}^{-1}$ & 0.0616 & 0.0668 & 0.0552 & 0.0687 \\
\hline$k_{-2}\left(T_{D}\right)$ & $\mathrm{s}^{-1}$ & 0.000761 & 0.339 & 0.000435 & 0.00133 \\
\hline$E_{\mathrm{A}}^{\mathrm{O}}$ & $\mathrm{kJ} \cdot \mathrm{mol}^{-1}$ & 68.6 & 0.0986 & 58.3 & 80.7 \\
\hline$E_{\mathrm{A}-1}$ & $\mathrm{~kJ} \cdot \mathrm{mol}_{-1}$ & 98.8 & 0.0311 & 93.9 & 104 \\
\hline$E_{\mathrm{A} 2}{ }^{-1}$ & $\mathrm{~kJ} \cdot \mathrm{mol}^{-1}$ & 52.0 & 0.0327 & 49.3 & 54.8 \\
\hline$E_{\mathrm{A}-2}^{2}$ & $\mathrm{~kJ} \cdot \mathrm{mol}^{-1}$ & 25.7 & 0.421 & 12.9 & 51.4 \\
\hline$\varepsilon_{444}^{2}(E) *$ & & 1.46 & 0.0950 & 1.24 & 1.70 \\
\hline$\varepsilon_{608}(\mathrm{E})^{*}$ & & 1.21 & 0.100 & 1.02 & 1.42 \\
\hline$\varepsilon_{590}(\mathrm{E})^{*}$ & & 0.118 & 1.18 & 0.0169 & 0.822 \\
\hline
\end{tabular}

* $\varepsilon_{444}^{\prime}(\mathrm{E}), \varepsilon_{608}^{\prime}(\mathrm{E})$ and $\varepsilon_{590}^{\prime}(\mathrm{E})$ are varied relative to $\varepsilon_{444}^{\prime}\left(\mathrm{I}_{\mathrm{c}}\right), \varepsilon_{608}^{\prime}\left(\mathrm{I}_{\mathrm{c}}\right)$ and $\varepsilon_{590}^{\prime}\left(\mathrm{II}_{\mathrm{c}}\right)$ respectively, which are set to 1.0.

and (2) respectively. Whereas the difference between the $444-463 \mathrm{~nm}$ and $608-630 \mathrm{~nm}$ traces becomes more marked as the temperature is lowered for both experiment and model (1), the difference becomes less marked for model (2). The reason for this is seen by comparing Figs. 5 and 6, which show the relationship of the computed percentage absorbance changes to the computed kinetics of the individual species for models (1) and (2) respectively. As the temperature is lowered, the maximal concentration of species $I_{c}$

Vol. 175 


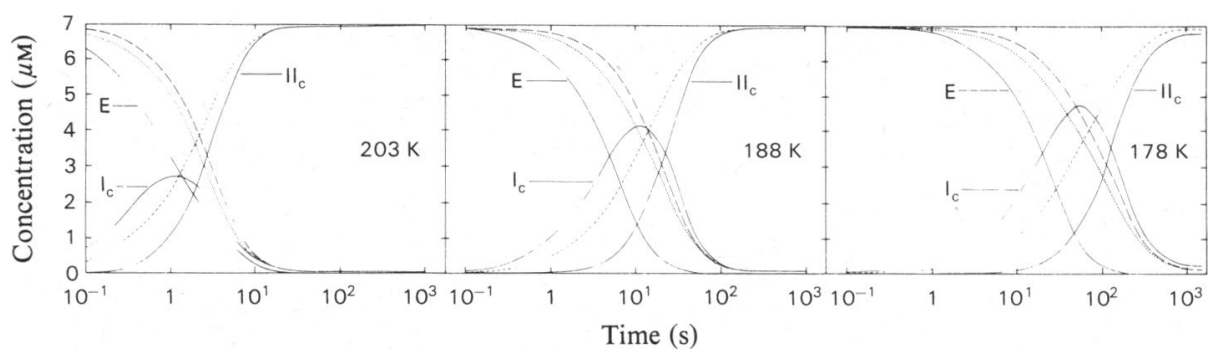

Fig. 5. Computed reaction kinetics of the individual intermediates and their relationship to the theoretical absorbance changes (in units of concentration) for model (1) in the reaction of fully reduced membrane-bound cytochrome oxidase with CO The theoretical kinetics at the three wavelength pairs for model (1) are shown as:,$- 444-463 \mathrm{~nm} ; \cdots, 608-630 \mathrm{~nm}$; ,$--- 590-630 \mathrm{~nm}$. The conditions immediately after flash photolysis (i.e. at $t=0 \mathrm{~s}$ ) are: $7 \mu \mathrm{M}-\mathrm{E}$ and $1.2 \mathrm{~mm}-\mathrm{CO}$.

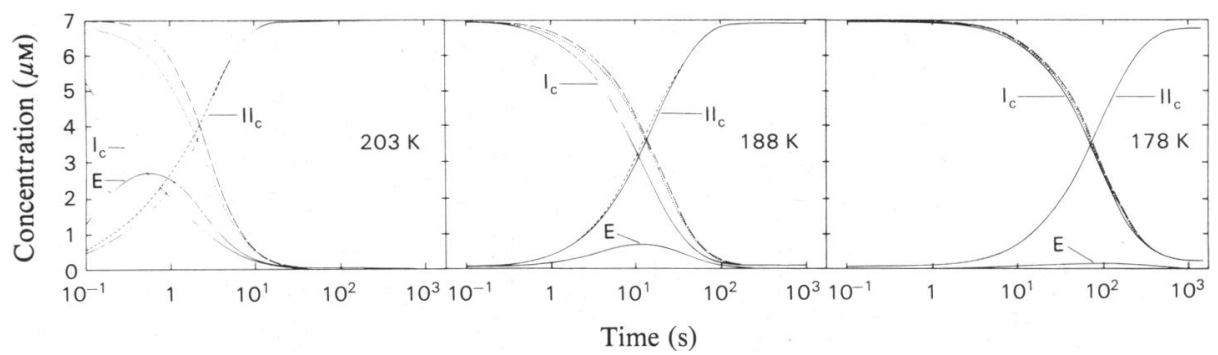

Fig. 6. Computed reaction kinetics of the individual intermediates and their relationship to the theoretical absorbance changes (in units of concentration) for model (2) in the reaction of fully reduced membrane-bound cytochrome oxidase with $C O$ The theoretical kinetics at the three wavelength pairs for model 2 are shown as:,$- 444-463 \mathrm{~nm}$; $\cdots, 608-630 \mathrm{~nm}$; ,$--- 590-630 \mathrm{~nm}$. The conditions immediately after flash photolysis (i.e. at $t=0 \mathrm{~s}$ ) are: $7 \mu \mathrm{M}-\mathrm{I}_{\mathrm{c}}$ and $1.2 \mathrm{mM}-\mathrm{CO}$. At $178 \mathrm{~K}$ the kinetics at $590-630 \mathrm{~nm}$ are superimposed on those of $\mathrm{II}_{\mathrm{c}}$.

increases in model (1), whereas the maximal concentration of species $\mathrm{E}$ decreases in model (2) until at $178 \mathrm{~K}$ it is almost negligible. Since for model (1):

$$
W_{444}(t)-W_{608}(t)=\mathrm{I}_{\mathrm{c}}(t)\left[\varepsilon_{444}^{\prime}\left(\mathrm{I}_{\mathrm{c}}\right)-\varepsilon_{608}^{\prime}\left(\mathrm{I}_{\mathrm{c}}\right)\right]
$$

and for model 2 :

$$
W_{444}(t)-W_{608}(t)=\mathrm{E}(t)\left[\varepsilon_{444}^{\prime}(\mathrm{E})-\varepsilon_{608}^{\prime}(\mathrm{E})\right]
$$

it follows that, as the temperature is lowered, the difference $\left[W_{444}(t)-W_{608}(t)\right]_{\max }$. will increase for model (1) and decrease for model (2). Similarly, as the temperature is lowered, so the difference

$$
\begin{gathered}
\left\{\left[B-W_{590}(t)\right]-W_{444}(t)\right\}_{\max } \text { and } \\
\left\{\left[B-W_{590}(t)\right]-W_{608}(t)\right\}_{\max } .
\end{gathered}
$$

will increase for model (1) (as is the case experimentally) and decrease for model (2), since for model (1):

$$
\left[B-W_{590}(t)\right]-W_{x}(t)=\mathrm{I}_{\mathrm{c}}(t)\left[1-\varepsilon_{590}^{\prime}\left(\mathrm{I}_{\mathrm{c}}\right)-\varepsilon_{x}^{\prime}\left(\mathrm{I}_{\mathrm{c}}\right)\right]
$$

and for model (2):

$$
\left[B-W_{590}(t)\right]-W_{x}(t)=\mathrm{E}(t)\left[1-\varepsilon_{590}^{\prime}(\mathrm{E})-\varepsilon_{x}^{\prime}(\mathrm{E})\right]
$$

where the subscript $x$ stands for 444 or $608 \mathrm{~nm}$ and $B$ is the total concentration of cytochrome oxidase, bound and unbound.

Eqns. (15), (16), (17) and (18) are of great importance, since they indicate that the difference in behaviour between the two models, as measured by the temperature-dependence of the difference between the traces of any two wavelength pairs is solely dependent on the different temperature-dependence of $I_{c}(t)$ and $\mathrm{E}(t)$ in models (1) and (2) respectively. For model (1):

$$
\mathrm{I}_{\mathrm{c}}(t)=k_{+1}\left[\mathrm{CO}_{\mathrm{p}}\right] B\left[a_{1}+a_{2} \exp \left(-\gamma_{1} t\right)+a_{3} \exp \left(-\gamma_{2} t\right)\right]
$$

and for model (2):

$$
\mathrm{E}(t)=k_{-1} B\left[a_{1}+a_{2} \exp \left(-\gamma_{1} t\right)+a_{3} \exp \left(-\gamma_{2} t\right)\right]
$$

where $\gamma_{1}$ and $\gamma_{2}$ are the observed rate constants for the fast and slow phases of the reaction respectively and $a_{1}, a_{2}$ and $a_{3}$ are functions of $\gamma_{1}, \gamma_{2}$ and the rate constants (for the derivation see Appendix I). It 
should be noted that $\gamma_{1}$ and $\gamma_{2}$ are the same for both models and are roots of the quadratic equation:

$$
\begin{gathered}
\gamma^{2}+\gamma\left(k_{+1}\left[\mathrm{CO}_{\mathrm{p}}\right]+k_{+2}+k_{-1}+k_{-2}\right)+ \\
k_{+1}\left[\mathrm{CO}_{\mathrm{p}}\right]\left(k_{+2}+k_{-2}\right)+k_{-1} k_{-2}=0
\end{gathered}
$$

taken with the reverse signs. From eqns. (19) and (20) it is readily seen that the difference between the traces of any two wavelength pairs as a function of temperature is dependent on the temperaturedependence of $k_{+1}$ in model (1) and of $k_{-1}$ in model (2).

The above discussion emphasizes the great importance of monitoring at least two wavelength pairs if models (1) and (2) are to be distinguished, since it is the dependence on temperature of the difference between the observed normalized progress curves at any two wavelength pairs which allows one to discriminate the two models. We also note that, when the progress curves from only a single wavelength pair (at a single $\mathrm{CO}$ concentration) are used as data, both models satisfy our triple statistical requirement and cannot be discriminated.

Although more complicated models are possible, the corresponding increase in the number of parameters which have to be optimized results in an under-determined system. We therefore conclude that, over the experimental temperature range and with the present data at three wavelength pairs (444-463 nm, 590-630 nm and 608-630 nm), model (1) is the only model that satisfies our three statistical criteria for goodness of fit.

\section{Comparison of the contributions of the intermediates to} the three wavelength pairs for model (1)

Eqn. (19) shows that the differences between the progress curves at the three wavelength pairs for model (1) are also a function of the relative extinction coefficients of species $I_{c}$. Looking at the optimized values of the relative extinction coefficients of species $I_{c}$ for model (1) given in Table 4, we observe that, within the errors specified, they are significantly different from 1.0 and

$$
\begin{aligned}
& \varepsilon_{444}^{\prime}(\mathrm{E})-\varepsilon_{444}^{\prime}\left(\mathrm{I}_{\mathrm{c}}\right)<\varepsilon_{444}^{\prime}\left(\mathrm{I}_{\mathrm{c}}\right) \\
& \varepsilon_{608}^{\prime}(\mathrm{E})-\varepsilon_{608}^{\prime}\left(\mathrm{I}_{\mathrm{c}}\right)<\varepsilon_{608}^{\prime}\left(\mathrm{I}_{\mathrm{c}}\right) \\
& \varepsilon_{444}^{\prime}\left(\mathrm{I}_{\mathrm{c}}\right)>\varepsilon_{608}^{\prime}\left(\mathrm{I}_{\mathrm{c}}\right) \\
& \varepsilon_{590}^{\prime}\left(\mathrm{II}_{\mathrm{c}}\right)-\varepsilon_{590}^{\prime}\left(\mathrm{I}_{\mathrm{c}}\right) \approx \varepsilon_{590}^{\prime}\left(\mathrm{I}_{\mathrm{c}}\right)
\end{aligned}
$$

The difference between $\Delta \varepsilon_{\mathrm{E}-\mathrm{I}_{\mathrm{c}}}^{i}$ and $\Delta \varepsilon_{\mathrm{I}_{\mathrm{c}}-\mathrm{II}_{\mathrm{c}}}^{i}$ at each wavelength as a function of ${ }^{c} \varepsilon_{i}^{\prime}\left(I_{c}\right)$ is obtained as follows. From the relations:

$$
\begin{aligned}
& \Delta \varepsilon_{\mathrm{I}_{\mathrm{c}}-\mathrm{II}_{\mathrm{c}}}^{444}=\Delta \varepsilon_{\mathrm{E}-\mathrm{I}_{\mathrm{c}}}^{444} \varepsilon_{444}^{\prime}\left(\mathrm{I}_{\mathrm{c}}\right) \\
& \Delta \varepsilon_{\mathrm{I}_{\mathrm{c}}-1 \mathrm{I}_{\mathrm{c}}}^{6-1}=\Delta \varepsilon_{\mathrm{E}-\mathrm{II}_{\mathrm{c}}}^{60} \varepsilon_{608}^{\prime}\left(\mathrm{I}_{\mathrm{c}}\right) \\
& \Delta \varepsilon_{\mathrm{I}_{\mathrm{c}}-\mathrm{E}}^{50}=\Delta \varepsilon_{\mathrm{II}_{\mathrm{c}}-\mathrm{E}}^{590} \varepsilon_{590}^{\prime}\left(\mathrm{I}_{\mathrm{c}}\right)
\end{aligned}
$$

it follows that:

$$
\begin{aligned}
& \Delta \varepsilon_{\mathrm{E}-\mathrm{I}_{\mathrm{c}}}^{444}-\Delta \varepsilon_{\mathrm{I}_{\mathrm{c}}-\mathrm{II}_{\mathrm{c}}}^{444}=\Delta \varepsilon_{\mathrm{E}-\mathrm{II}}^{444}\left[1-2 \varepsilon_{444}^{\prime}\left(\mathrm{I}_{\mathrm{c}}\right)\right] \\
& \Delta \varepsilon_{\mathrm{E}}^{608}-\Delta \varepsilon_{\mathrm{I}_{\mathrm{c}}-\mathrm{II}_{\mathrm{c}}}^{608}=\Delta \varepsilon_{\mathrm{E}-\mathrm{II}_{\mathrm{c}}}^{608}\left[1-2 \varepsilon_{608}^{\prime}\left(\mathrm{I}_{\mathrm{c}}\right)\right] \\
& \Delta \varepsilon_{\mathrm{E}-\mathrm{I}_{\mathrm{c}}}^{590}-\Delta \varepsilon_{\mathrm{I}_{\mathrm{c}}-\mathrm{II}_{\mathrm{c}}}^{590}=\Delta \varepsilon_{\mathrm{E}-\mathrm{II}_{\mathrm{c}}}^{59}\left[\varepsilon_{590}^{\prime}\left(\mathrm{I}_{\mathrm{c}}\right)-1\right]
\end{aligned}
$$

Combining eqns. (22) and (24) these results may be expressed in the form:

$$
\Delta \varepsilon_{\mathrm{E}-\mathrm{I}_{\mathrm{c}}}^{444}-\Delta \varepsilon_{\mathrm{I}_{\mathrm{c}}-\mathrm{II}_{\mathrm{e}}}^{44}<\Delta \varepsilon_{\mathrm{E}-\mathrm{I}_{\mathrm{c}}}^{608}-\Delta \varepsilon_{\mathrm{I}_{\mathrm{c}}-\mathrm{II}_{\mathrm{c}}}^{608}<\Delta \varepsilon_{\mathrm{E}-\mathrm{I}_{\mathrm{c}}}^{590}-\Delta \varepsilon_{\mathrm{I}_{\mathrm{c}}-\mathrm{II}_{\mathrm{c}}}^{50} \approx 0
$$

Thus at $590-630 \mathrm{~nm}$ the E-to- $\mathrm{I}_{\mathrm{c}}$ transition produces approximately the same absorption change as the $I_{c^{-}}$to-II $I_{c}$ transition. At $444-463 \mathrm{~nm}$ and $608-630 \mathrm{~nm}$, however, the absorption change for the E-to- $I_{c}$ transition is significantly smaller than that for the $I_{c}$ to- $\mathrm{II}_{\mathrm{c}}$ transition. Furthermore, the absorption change for the E-to- $I_{c}$ transition at $444-463 \mathrm{~nm}$ is significantly smaller than that at $608-630 \mathrm{~nm}$.

\section{Thermodynamics of $\mathrm{CO}$ binding}

In this section, the relevant equations, derived from classical transition-state theory (Bamford \& Tipper, 1969), for the calculation of the enthalpy of activation, the free energy of activation and the entropy of activation are presented, and the difference in the thermodynamics of the two models are summarized.

The enthalpy of activation $\left(\Delta H_{i}^{\neq}\right)$at a temperature $T_{j}$ is given by:

$$
\Delta H_{i}^{\ddagger}\left(T_{j}\right)=E_{\mathrm{A}_{i}}^{0}-R T_{j}(1+n)
$$

for a first-order reaction and by:

$$
\Delta H_{i}^{\ddagger}\left(T_{j}\right)=E_{\mathrm{A}_{i}}^{0}-R T_{j}(2+n)
$$

for a second-order reaction. As already discussed we take $n$ equal to zero [i.e. the condition for temperatureindependence of the frequency factor in eqn. (14)].

The free energy of activation $\left(\Delta G_{l}^{*}\right)$ is given by:

$$
\Delta G_{i}^{\ddagger}\left(T_{j}\right)=-R T_{j} \ln \left(\frac{h k_{i}\left(T_{j}\right)}{k_{\mathrm{B}} T_{j}}\right)
$$

where $k_{i}\left(T_{j}\right)$ is the corresponding value of the rate constant given by eqn. (14).

The entropy of activation $\left(\Delta S_{\imath}^{*}\right)$ is then given by:

$$
\begin{aligned}
\Delta S_{i}^{\ddagger}\left(T_{j}\right) & =\frac{\Delta H_{i}^{\ddagger}\left(T_{j}\right)-\Delta G_{i}^{\ddagger}\left(T_{j}\right)}{T_{J}} \\
& =\left[\ln \left(\frac{h k_{i}\left(T_{j}\right)}{k_{\mathrm{B}} T_{j}}\right)+\frac{\Delta H_{i}^{\ddagger}\left(T_{j}\right)}{R T_{J}}\right] R
\end{aligned}
$$

and the ratio of the number of quantum states, $W_{i}^{\prime} / W_{i}$, at two positions that differ in entropy by an amount $\Delta S_{l}^{*}$ is given by:

$$
\frac{W_{i}^{\prime}\left(T_{j}\right)}{W_{l}\left(T_{j}\right)}=\exp \left(\frac{\Delta S_{i}^{\ddagger}\left(T_{j}\right)}{R}\right)
$$


The equations for calculating the S.D. of these thermodynamic parameters from the S.D. In of the rate constants at $188 \mathrm{~K}$ and of the energies of activation (Tables 4 and 5), and of the correlation matrix (Tables 2 and 3) obtained by optimization, are given in Appendix II.

The enthalpies, free energies and entropies of activation at $188 \mathrm{~K}$ and the temperature-independent frequency factors for both models are collected in Table 6. In Fig. 7, the energies of activation, together with the free energies and entropies of activation at $188 \mathrm{~K}$, are plotted as a function of the reaction co-ordinate. In addition, the ratio of the number of quantum states, $W_{i}^{\prime} / W$, normalized to 1.0 in species $\mathrm{II}_{\mathrm{c}}$, is also shown in Fig. 7.

Comparing the values of the thermodynamic parameters for the two models, it can be seen that the only significant difference lies in the parameters governing the transition:

$$
\mathrm{E}+\mathrm{CO}_{\mathrm{p}} \rightarrow \mathrm{I}_{\mathrm{c}}
$$

The values of $E_{\mathrm{A}_{1}}, \Delta H_{1}^{*}, \Delta S_{1}^{*}$, and $\lambda_{1}$ are significantly lower in model (1). No significant difference, however, exists between $\Delta G_{1}^{*}(188 \mathrm{~K})$ in the two models.

Since model (2) failed to satisfy our three statistical criteria for goodness of fit, as already discussed, we will limit our further discussion to model (1).

Temperature-dependence of the thermodynamic parameters and rate constants for model (1)

In Table 7 , the values of $\Delta H^{*}, \Delta G^{\ddagger}, \Delta S^{*}$ and the rate constants at $140,178,203$ and $240 \mathrm{~K}$ are collected. (Note that the values of the thermodynamic para-
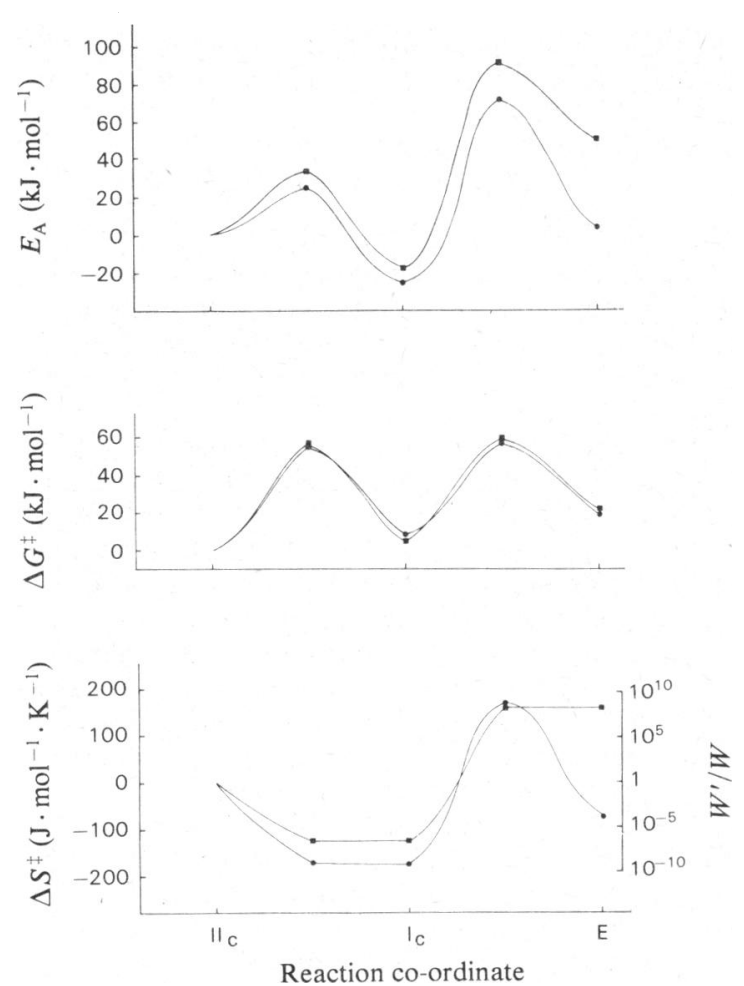

Fig. 7. Free energy and entropy of activation at $188 \mathrm{~K}$ together with the energy of activation as a function of the reaction co-ordinate for $\mathrm{CO}$ binding to fully reduced membrane-bound cytochrome oxidase as calculated by using both model (1) ( $\square$ ) and model (2) (•)

Table 6. Calculated values of the enthalpies $\left(\Delta H_{i}^{*}\right)$, free energies $\left(G_{i}^{*}\right)$ and entropies $\left(\Delta S_{i}^{*}\right)$ of activation at $188 K$ and the temperature-independent frequency factors $\left(\lambda_{i}\right)$ for models $(1)$ and $(2)$

Standard deviations are shown in parentheses. The formulae for calculating the standard deviations from the S.D. In $_{\text {of }}$ the relevant optimized parameters (given in Tables 3 and 4 ) and the correlation matrices (Tables 2 and 3 ) are given in Appendix II.

Transition

$$
\mathrm{E}+\mathrm{CO}_{\mathrm{p}} \rightarrow \mathrm{I}_{\mathrm{c}}
$$

$\mathrm{I}_{\mathbf{c}} \rightarrow \mathrm{E}+\mathrm{CO}_{\mathrm{p}}$

$\mathrm{I}_{\mathrm{c}} \rightarrow \mathrm{II}_{\mathrm{c}}$

$\mathrm{II}_{\mathrm{c}} \rightarrow \mathrm{I}_{\mathrm{c}}$

\begin{tabular}{|c|c|}
\hline $\begin{array}{l}\Delta H_{1}^{*} \\
\Delta G_{1}^{*} \\
\Delta S_{1}^{*} \\
\log \left(\lambda_{1}\right)\end{array}$ & $\begin{array}{l}\mathrm{kJ} \cdot \mathrm{mol}^{-1} \\
\mathrm{~kJ} \cdot \mathrm{mol}^{-1} \\
\mathrm{~J} \cdot \mathrm{mol}^{-1} \cdot \mathrm{K}^{-1} \\
\mathbf{M}^{-1} \cdot \mathrm{s}^{-1}\end{array}$ \\
\hline $\begin{array}{l}\Delta H_{-1}^{*} \\
\Delta G_{-1}^{*} \\
\Delta S_{-1}^{*} \\
\log \left(\lambda_{-1}^{*}\right)\end{array}$ & $\begin{array}{l}\mathrm{kJ} \cdot \mathrm{mol}^{-1} \\
\mathrm{~kJ} \cdot \mathrm{mol}^{-1} \\
\mathrm{~J} \cdot \mathrm{mol}^{-1} \cdot \mathrm{K}^{-1} \\
\mathrm{~s}^{-1}\end{array}$ \\
\hline $\begin{array}{l}\Delta H_{2}^{ \pm} \\
\Delta G_{2}^{*} \\
\Delta S_{2}^{*} \\
\log \left(\lambda_{2}\right)\end{array}$ & $\begin{array}{l}\mathrm{kJ} \cdot \mathrm{mol}^{-1} \\
\mathrm{KJ} \cdot \mathrm{mol}^{-1} \\
\mathrm{~J} \cdot \mathrm{mol}^{-1} \cdot \mathrm{K}^{-1} \\
\mathrm{~s}^{-1}\end{array}$ \\
\hline $\begin{array}{l}\Delta H_{-2}^{*} \\
\Delta G_{-2}^{*} \\
\Delta S_{-2}^{*} \\
\log \left(\lambda_{-2}\right)\end{array}$ & $\begin{array}{l}\mathrm{kJ} \cdot \mathrm{mol}^{-1} \\
\mathrm{KJ} \cdot \mathrm{mol}^{-1} \\
\mathrm{~J} \cdot \mathrm{mol}^{-1} \cdot \mathrm{K}^{-1} \\
\mathrm{~s}^{-1}\end{array}$ \\
\hline
\end{tabular}

Parameter
Model (1)

$37.7( \pm 0.916)$

$37.7( \pm 0.156)$

$0.202( \pm 4.67)$

$13.5( \pm 0.565)$

$108( \pm 5.09)$

$54.2( \pm 0.770)$

$286( \pm 23.1)$

$28.0( \pm 2.78)$

$50.3( \pm 1.32)$

$50.2( \pm 0.0643)$

$0.569( \pm 7.17)$

$13.1( \pm 0.847)$

$32.9( \pm 7.45)$

$56.2( \pm 0.192)$

$-124( \pm 39.4)$

$5.56( \pm 4.72)$
Model (2)

$65.5( \pm 6.76)$

$38.7( \pm 0.770)$

$143( \pm 33.0)$

$20.9( \pm 3.74)$

$97.3( \pm 3.07)$

$51.3( \pm 0.795)$

$245( \pm 13.5)$

$25.8( \pm 1.66)$

$50.4( \pm 1.70)$

$49.7( \pm 0.104)$

$3.93( \pm 9.53)$

$13.2( \pm 1.11)$

$24.2( \pm 10.8)$

$56.5( \pm 0.530)$

$-172( \pm 58.1)$

$5.03( \pm 6.99)$ 
Table 7. Effect of temperature on the rate constants and free energies $\left(\Delta G_{i}^{*}\right)$, entropies $\left(\Delta S_{i}^{*}\right)$ and enthalpies $\left(\Delta H_{i}^{*}\right)$ of activation for model (1)

The S.D.In of the rate constants and the standard deviations of the other parameters are shown in parentheses. The formulae for calculating the S.D. In $_{\text {of }}$ the rate constants and the standard deviations of $\Delta G_{i}^{*}, \Delta S_{i}^{*}$ and $\Delta H_{i}^{*}$ at any given temperature from the S.D.In of the optimized rate constants and energies of activation (given in Table 4 for model 1) and the correlation matrix (Table 2 for model 1) are given in Appendix I.

Parameter Temperature (K) $\ldots 140$

178

203

240

$k_{+1}\left(\mathrm{M}^{-1} \cdot \mathrm{s}^{-1}\right)$

$1.69 \times 10^{-2}(0.252)$

$k_{-1}\left(\mathrm{~s}^{-1}\right)$

$1.25 \times 10^{-13}(1.59)$

$k_{+2}\left(\mathrm{~s}^{-1}\right)$

$k_{-2}\left(\mathrm{~s}^{-1}\right)$

$5.04 \times 10^{-7}(0.276)$

$3.04 \times 10^{1}(0.154)$

$6.73 \times 10^{-5}(0.671)$

$6.83 \times 10^{-3}(0.0488)$

$9.11 \times 10^{2}(0.101)$

$6.13 \times 10^{-1}(0.270)$

$2.74 \times 10^{-4}(0.377)$

$5.12 \times 10^{-1}(0.0873)$

$4.83 \times 10^{-3}(0.401)$

$38.2( \pm 0.293)$

$37.8( \pm 0.228)$

$68.0( \pm 1.85)$

$57.1( \pm 0.993)$

$\Delta G_{-1}^{*}\left(\mathrm{~kJ} \cdot \mathrm{mol}^{-1}\right)$

$50.3( \pm 0.321)$

$50.2( \pm 0.0663)$

$\Delta G_{-2}^{ \pm}\left(\mathrm{kJ} \cdot \mathrm{mol}^{-1}\right)$

$50.3( \pm 1.97)$

$55.0( \pm 0.558)$

$2.64( \pm 6.32)$

$0.657( \pm 4.91)$

$289( \pm 24.0)$

$287( \pm 28.7)$

$1.78( \pm 10.6)$

$1.02( \pm 7.60)$

$\Delta S_{2}^{\neq}\left(\mathrm{J} \cdot \mathrm{mol}^{-1} \cdot \mathrm{K}^{-1}\right)$

$-121( \pm 51.8)$

$38.5( \pm 0.916)$

$-123( \pm 41.2)$

$37.9( \pm 0.916)$

$37.6( \pm 0.170)$

$49.9( \pm 0.456)$

$50.2( \pm 0.147)$

$58.1( \pm 0.678)$

$-0.433( \pm 4.34)$

$286( \pm 24.4)$

$-0.0690( \pm 6.84)$

$-124( \pm 36.1)$

$37.5( \pm 0.916)$

$108( \pm 5.09)$

$108( \pm 5.09)$

$50.7( \pm 1.32)$

$50.4( \pm 1.32)$

$\Delta H_{-1}^{+}\left(\mathrm{kJ} \cdot \mathrm{mol}^{-1}\right)$

$\Delta H_{-2}^{+}\left(\mathrm{kJ} \cdot \mathrm{mol}^{-1}\right)$

$33.3( \pm 7.45)$

$33.0( \pm 7.45)$

$50.2( \pm 1.32)$

$32.8( \pm 7.45)$

$3.80 \times 10^{4}(0.138)$

$1.36 \times 10^{4}(0.268)$

$5.84 \times 10^{1}(0.203)$

$1.13 \times 10^{-1}(1.00)$

$37.3( \pm 0.275)$

$39.4( \pm 0.535)$

$50.2( \pm 0.800)$

$62.7( \pm 1.16)$

$-1.83( \pm 3.64)$

$284( \pm 19.1)$

$-1.47( \pm 6.38)$

$-126( \pm 30.2)$

$36.9( \pm 0.916)$

$108( \pm 5.09)$

$49.9( \pm 1.32)$

$32.5( \pm 7.45)$

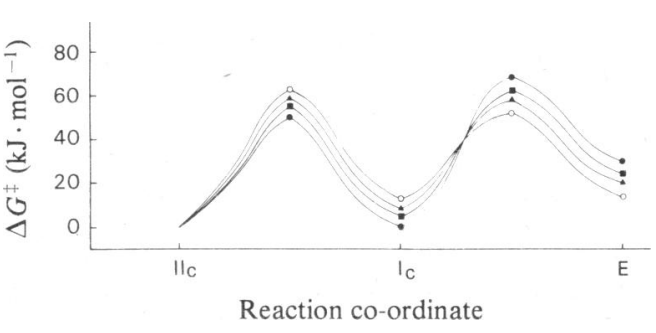

Fig. 8. Free energy of activation as a function of the reaction co-ordinate for $\mathrm{CO}$ binding to fully reduced membrane-bound cytochrome oxidase at $140 \mathrm{~K}(\bullet), 178 \mathrm{~K}$ $(\square), 203 K(\Delta)$ and $240 K(O)$ as calculated by using model (1)

meters and rate constants from 140 to $178 \mathrm{~K}$ and 203 to $240 \mathrm{~K}$ are extrapolated from the values obtained by optimization over the experimental range, 178$203 \mathrm{~K}$ inclusive; the justification for such an extrapolation has been discussed previously.) The temperature-dependence, over the $140-240 \mathrm{~K}$ range, of $\Delta G^{*}$ plotted as a function of the reaction co-ordinate, and of the rate constants is shown in Figs. 8 and 9 respectively. Since $\left[\mathrm{CO}_{\mathrm{p}}\right] \gg B$ (where $B$ is the total concentration of cytochrome oxidase) and:

$$
k_{+1}\left[\mathrm{CO}_{\mathrm{p}}\right]+k_{-1} \gg k_{+2}, k_{-2}
$$

(which is the condition for rapid pre-equilibration of the step $\mathrm{E}+\mathrm{CO}_{\mathrm{p}} \rightleftharpoons \mathrm{I}_{\mathrm{c}}$ ) we can write:

$$
\gamma_{2} \approx k_{-2}+k_{+2}\left(1+\frac{k_{-1}}{k_{+1}\left[\mathrm{CO}_{\mathrm{p}}\right]}\right)^{-1}
$$

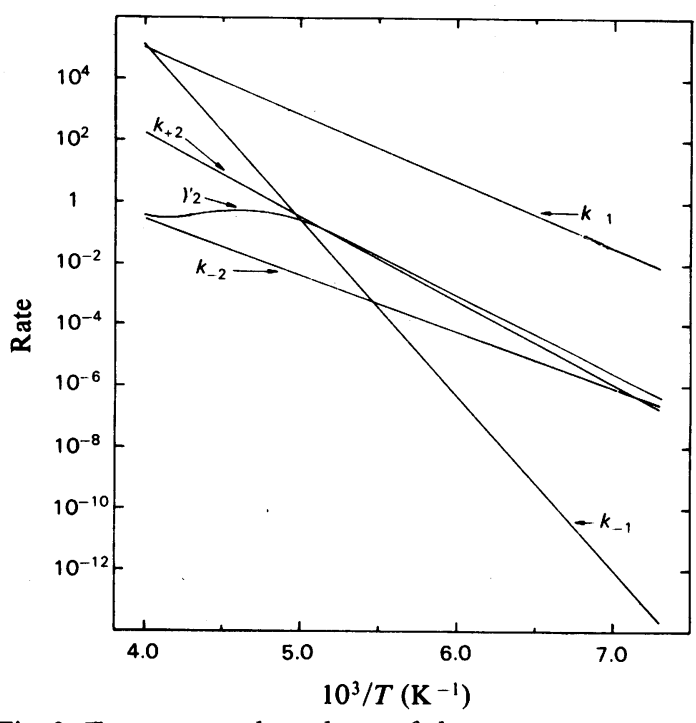

Fig. 9. Temperature-dependence of the rate constants over the 140-240 Krange for model (1)

The units of $k_{+1}$ are $\mathrm{M}^{-1} \cdot \mathrm{s}^{-1}$; the units of all the other rate constants are $\mathrm{s}^{-1}$.

where $\gamma_{2}$ is the observed rate constant for the slow phase. A plot of $\gamma_{2}$ as a function of temperature is included in Fig. 9.

Over the 140-240K range it can be seen that, within the errors specified, both $\Delta S_{i}^{*}$ and $\Delta G_{2}^{*}$ are temperature-independent. The reaction kinetics,

Vol. 175 
however, can be divided into four distinct temperature zones. Below 140K:

$$
k_{-2}>k_{+2}
$$

and

$$
\Delta G_{2}^{\ddagger}>\Delta G_{-2}^{\ddagger}
$$

so that at equilibrium:

$$
\left[\mathrm{I}_{\mathrm{c}}\right]>\left[\mathrm{II}_{\mathrm{c}}\right]
$$

Between 140 and $202 \mathrm{~K}$ :

$$
k_{+1}\left[\mathrm{CO}_{\mathrm{p}}\right]>k_{-1} \quad k_{+2}>k_{-2} \quad k_{+2}>k_{-1}
$$

and

$$
\Delta G_{1}^{\ddagger}<\Delta G_{-1}^{\ddagger} \quad \Delta G_{2}^{\ddagger}<\Delta G_{-2}^{\ddagger} \quad \Delta G_{2}^{\ddagger}<\Delta G_{-1}^{\ddagger}
$$

so that the reaction proceeds down a free-energy gradient towards species $\mathrm{II}_{\mathrm{c}}$. In this temperature range $\gamma_{2}$ assumes a maximum value of $k_{+2}+k_{-2}$. Between 202 and 240K:

$$
k_{-1}>k_{+2}
$$

and

$$
\Delta G_{2}^{\ddagger}>\Delta G_{-1}^{\ddagger}
$$

so that $\mathrm{CO}$ proceeds towards species $\mathrm{II}_{\mathrm{c}}$ by a random walk process. After the formation of species $I_{c}$, the reaction has a larger probability of returning to species $\mathrm{E}$ than to proceed to species $\mathrm{II}_{\mathrm{c}}$. Thus $\mathrm{CO}$ has to shuttle several times between species $E$ and $I_{c}$ before proceeding to species $\mathrm{II}_{\mathrm{c}}$. The condition $k_{-1}>k_{+2}$ is reflected in the pronounced deviation from linearity in the temperature-dependence of $\gamma_{2}$. Above $248 \mathrm{~K}$, the melting point of the $30 \%$ ethylene glycol solvent, the optimized values of the activation energies and rate constants at $188 \mathrm{~K}$ predict that:

$$
k_{-1}>k_{+1}\left[\mathrm{CO}_{\mathrm{p}}\right] \quad k_{-1}>k_{+2}
$$

Extrapolation to $293 \mathrm{~K}$ leads to a value of $14 \mathrm{M}^{-1}$ for the overall equilibrium constant of the reaction, as compared with values between 3.3 and $5.0 \mu \mathrm{M}^{-1}$ found by Gibson \& Greenwood (1963). This indicates that the transition from the solid state to the liquid state is accompanied by large changes in the values of the thermodynamic parameters governing the reaction:

$$
\mathrm{E}+\mathrm{CO}_{\mathrm{p}} \rightleftharpoons \mathrm{I}_{\mathrm{c}}
$$

This could be achieved by an increase in $\Delta S_{1}^{*}$ (and therefore in $\lambda_{1}$ ) and/or a decrease in $\Delta S_{-1}^{\neq}$(and therefore $\left.\lambda_{-1}\right)$. Such changes would be expected of a 'pocket' with a non-polar character containing the active site. This is consistent with the finding that the single C-O stretch band at $1963.5 \mathrm{~cm}^{-1}$ for the cytochrome oxidase-CO complex has a very narrow bandwidth $\left(\Delta v_{t}, 6 \mathrm{~cm}^{-1}\right)$ as compared with the wide bandwidth $\left(\Delta v_{t}, 20 \mathrm{~cm}^{-1}\right)$ of the single $\mathrm{C}-\mathrm{O}$ stretch band at $1967 \mathrm{~cm}^{-1}$ for the isolated haem A-CO complex, the same Tween/phosphate buffer and temperature being used in both cases (Caughey et al., 1970). Therefore the environment about the CO ligand is quite different in cytochrome oxidase and isolated haem $\mathrm{A}$. These observations indicate that the $\mathrm{CO}$ ligand in the cytochrome oxidase-CO complex must be isolated from the environment of the external solvent and experience uniform and stable solvation interactions; this is consistent with a highly ordered ligand environment of a very non-polar character (Yoshikawa et al., 1977).

The characterization of the nature of the changes in the thermodynamic parameters during the solidliquid state transition, in particular the question of continuous change versus discontinuous change, as well as the characterization of the liquid-state kinetics, will require the development of greater time resolution for the multichannel spectrophotometer. Furthermore the determination of the kinetics of $\mathrm{CO}$ exchange between the solvent and the 'pocket' of the active site in the liquid state will require an experiment conducted over a wide range of $\mathrm{CO}$ concentrations.

\section{Thermodynamics of $\mathrm{CO}$ binding in the $140-240 \mathrm{~K}$ region for model (1)}

The formation of species $\mathrm{I}_{c}$ from species $\mathrm{E}$ and $\mathrm{CO}_{p}$ is accompanied by a decrease in enthalpy, free energy and entropy. The decrease in entropy $\left(286 \mathrm{~J} \cdot \mathrm{mol}^{-1}\right.$. $\mathrm{K}^{-1}$ ), corresponding to a decrease by a factor of the order of $9 \times 10^{14}$ in the number of quantum states, is too large to be accounted for by considering only the states of the $\mathrm{CO}$ molecule. Interestingly, the formation of the activated complex, $I_{c}^{*}$, from species $\mathrm{E}$ and $\mathrm{CO}_{\mathrm{p}}$ is not accompanied by any significant change in entropy, so that the overall entropy change, $\Delta S_{\mathrm{E} \leftrightarrow \mathrm{Ic}}$, for the reaction:

$$
\mathrm{E}+\mathrm{CO}_{\mathrm{p}} \rightleftharpoons \mathrm{I}_{\mathrm{c}}
$$

is approximately equal to $\Delta S_{-1}^{*}$. Thus we deduce that $\mathrm{CO}$ is only loosely bound to cytochrome oxidase in $I_{c}^{ \pm}$, and any loss in translational and rotational freedom of the $\mathrm{CO}$ molecule is accompanied by a corresponding increase in translational and rotational freedom in another part of the biomolecule. In addition, the value of $E_{\mathrm{A}_{1}}^{\mathbf{0}}$ is approximately half that of $E_{A_{-1}}^{0}$ so that $I_{c}^{*}$ is reached early in the forward reaction process and its electronic structure closely resembles that of the reactants, species $E$ and $C O$.

The formation of species $\mathrm{II}_{c}$ from species $I_{c}$ is accompanied by an increase in enthalpy and entropy, and a decrease in free energy. The increase in entropy $\left(126 \mathrm{~J} \cdot \mathrm{mol}^{-1} \cdot \mathrm{K}^{-1}\right)$, corresponding to an increase by a factor of the order of $3 \times 10^{6}$ in the number of quantum states, outweighs the unfavourable enthalpy change and provides the driving force for the forward reaction. The formation of the activated complex, $\mathrm{II}_{c}^{*}$, from species $\mathrm{I}_{\mathrm{c}}$ is not accompanied by any 
significant change in entropy. However, $E_{\mathbf{A}_{2}}^{0}$ is significantly larger than $E_{\mathrm{A}_{-2}}^{0}$ (see Table 4), so that $\mathrm{II}_{\mathrm{c}}^{+}$ is reached late in the forward reaction process. Thus, although the geometric structure of $\mathrm{II}_{\mathrm{c}}^{*}$ is very similar to that of species $I_{c}$, its electronic structure resembles that of species $\mathrm{II}_{\mathrm{c}}$ more closely than that of species $\mathrm{I}_{\mathrm{c}}$.

\section{Chemical nature of the intermediates}

In this section the possible identity of the intermediates is suggested on the basis of data from this paper, from potentiometric studies, from magneticsusceptibility measurements and from i.r. spectroscopy.

The potentiometric studies by Lindsay \& Wilson (1974) demonstrated that the formation of the CO compound is a two-electron process $(n=2)$, the Nernst plot showing a strict two-electron titration curve $(30 \mathrm{mV}$ per $\log$ unit). This is in agreement with titration studies of the CO-induced absorbance changes at 432 and $590 \mathrm{~nm}$, which showed that the $\mathrm{CO}$ compound is formed completely only when two electrons are taken up by cytochrome oxidase (Wever et al., 1977). These two observations suggest that both the iron of haem $a_{3}$ and its associated copper atom participate co-operatively in $\mathrm{CO}$ binding, a hypothesis consistent with the observation that the midpoint potential value of the $\mathrm{CO}$ complex becomes $30 \mathrm{mV}$ more positive for each 10 -fold increase in CO concentration (Lindsay \& Wilson, 1974). Further support for this hypothesis comes from magnetic-susceptibility measurements by both magnetic circular dichroism (Palmer et al., 1976; Thomson et al., 1976, 1977) and nuclear magnetic resonance (Falk et al., 1977), which have shown that, in the fully oxidized state, the $\mathrm{Fe}^{3+}$ ion of haem $a_{3}$ and its associated $\mathrm{Cu}^{2+}$ ion are anti-ferromagnetically coupled. The strong coupling found requires electronic overlap between the two metal ions. Thus the separation between these two metal ions must certainly be within $0.5 \mathrm{~nm}$ ( $5 \AA)$, a distance small enough to allow for the possibility of a $\mathrm{CO}$ bridge structure between them.

I.r. spectroscopy (Caughey et al., 1970, 1976; Volpe et al., 1975) has revealed the presence of a single $\mathrm{C}-\mathrm{O}$ stretch band at $1963.5 \mathrm{~cm}^{-1}$ for the fully reduced cytochrome oxidase-CO complex. This frequency is too high to account for a $\mathrm{CO}$ bridge structure between two metal ions, which would be expected to have a $\mathrm{C}-\mathrm{O}$ stretch band in the range $1700-1800 \mathrm{~cm}^{-1}$ (Cotton \& Wilkinson, 1972), and provides firm evidence that $\mathrm{CO}$ is bound to a single metal ion in a terminal end-on fashion. Variabletemperature magnetic-circular-dichroism spectra (Thomson et al., 1977) have shown that in the fully reduced state cytochrome oxidase is highly paramagnetic, with a high-spin haem $a_{3}$ iron and a lowspin haem $a$ iron. On CO binding, the iron of haem $a_{3}$ becomes low-spin. Thus, in the fully reduced cytochrome oxidase-CO complex, $\mathrm{CO}$ must be bound to the iron of haem $a_{3}$.

The apparently conflicting data from potentiometric studies and i.r. spectroscopy can be resolved by the following mechanism (Fig. 10), which accounts for the entropy changes reported in this paper.

The first step involves the formation of a $\mathrm{CO}$ bridge structure between the iron of haem $a_{3}$ and its associated copper atom with a predicted $\mathrm{C}-\mathrm{O}$ stretch band in the range $1700-1800 \mathrm{~cm}^{-1}$ for species $I_{c}$. This accounts for the $n=2$ behaviour of the CO complex and the large decrease in entropy $\left(286 \mathrm{~J} \cdot \mathrm{mol}^{-1} \cdot \mathrm{K}^{-1}\right)$ for the E-to-I $\mathrm{I}_{\mathrm{c}}$ transition.

In the second step, the bond between $\mathrm{CO}$ and the copper atom is broken, resulting in the formation of species $\mathrm{II}_{\mathrm{c}}$ in which $\mathrm{CO}$ is bound only to the iron of haem $a_{3}$. This accounts for the observed $\mathrm{C}-\mathrm{O}$ stretch band at $1963.5 \mathrm{~cm}^{-1}$ and the increase in entropy $\left(126 \mathrm{~J} \cdot \mathrm{mol}^{-1} \cdot \mathrm{K}^{-1}\right)$ for the $\mathrm{I}_{\mathrm{c}}$ to $\mathrm{II}_{\mathrm{c}}$ transition.

We thank Professor B. Chance, Dr. M. R. Hollaway and Mr. A. R. Curtis for many stimulating discussions, continual encouragement and support. We also thank the Johnson Research Foundation (University of Pennsylvania) for experimental facilities and the University College London Computer Centre for computer facilities. G. M. C. acknowledges a Carlo Campolin Scholarship.

\section{References}

Alberding, N., Austin, R. H., Chan, S. S., Eisenstein, L., Frauenfelder, H., Gunsalus, I. C. \& Nerdlund, T. M. (1976) J. Chem. Phys. 65, 4701-4711

Austin, R. H., Beeson, K. W., Eisenstein, L., Frauenfelder, H. \& Gunsalus, I. C. (1975) Biochemistry 14, 5355-5373

Bamford, C. H. \& Tipper, C. F. H. (1969) Comprehensive Kinetics, vol. 2, Elsevier/North-Holland, Amsterdam

Caughey, W. S., Bayne, R. A. \& McCoy, S. (1970) Chem. Commun. 950-951

Caughey, W.S., Wallace, W. J., Volpe, J. A. \& Yoshikawa, S. (1976) Enzymes 3rd Ed. 13, 299-344

Chance, B., Legallais, V., Sorge, J. \& Graham, N. (1975a) Anal. Biochem. 66, 498-514

Chance, B., Graham, N. \& Legallais, V. (1975b) Anal. Biochem. 67, 552-579

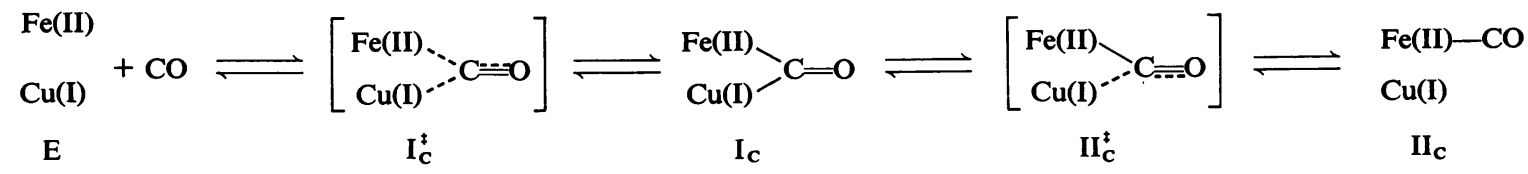

Fig. 10. Proposed mechanism for the reaction of fully reduced membrane-bound cytochrome oxidase with $C O$ 
Chance, B., Saronio, C. \& Leigh, J. S. (1975c) J. Biol. Chem. 250, 9226-9237

Chance, B., Leigh, J. S. \& Warren, A. (1977) BBA Libr. 14, 1-10

Chance, B., Saronio, C., Leigh, J. S., Ingledew, W. J. \& King, T. E. (1978) Biochem. J. 171, 787-798

Chance, E. M. \& Curtis, A. R. (1970) FEBS Lett. 7, 47-50 Chance, E. M., Curtis, A. R., Jones, I. P., \& Kirby, C. R. (1977) A.E.R.E. Rep. No. R. 8775, A.E.R.E., Harwell

Clore, G. M. \& Chance, E. M. (1978a) Biochem. J. 173, 799-810

Clore, G. M. \& Chance, E. M. (1978b) Biochem. J. 173, 811-820

Cotton, F. A. \& Wilkinson, G. (1972) Advanced Inorganic Chemistry, 3rd edn., Interscience, New York

Curtis, A. R.(1976) A.E.R.E.Rep. No.C.S.S. 26, A.E.R.E., Harwell

Curtis, A. R. (1977) A.E.R.E. Rep. No. C.S.S. 50, A.E.R.E., Harwell

Curtis, A. R. (1978) A.E.R.E. Rep. No. C.S.S.54, A.E.R.E., Harwell

Curtis, A. R. \& Chance, E. M. (1972) in Analysis and Simulation of Biochemical Systems (Hemker, H. C. \& Hess, B., eds.), vol. 25, pp. 39-57, Elsevier NorthHolland, Amsterdam

Curtis, A. R. \& Kirby, C. R. (1977) A.E.R.E. Rep. No. C.S.S. 50, A.E.R.E., Harwell

Falk, K.-E., Vanngard, T. \& Angstrom, J. (1977) FEBS Lett. 75, 23-27

Gear, C. W. (1971) Commun. ACM 14, 176-179

Gibson, Q. H. \& Greenwood, C. (1963) Biochem. J. 86, 541-554
Goldanskii, V. I. (1976) Annu. Rev. Phys. Chem. 27, 85-126

Hartzell, C. H. \& Beinert, H. (1974) Biochim. Biophys. Acta 368, 318-338

Lin, S. H. \& Eyring, H. (1972) Proc. Natl. Acad. Sci. U.S.A. 69, 3192-3194

Lindsay, J. G. \& Wilson, D. F. (1974) FEBS Lett. 48, 45-49

Low, H. \& Vallin, I. (1963) Biochim. Biophys. Acta 69, 361-374

Palmer, G., Babcock, G. T. \& Vickery, L. E. (1976) Proc. Natl. Acad. Sci. U.S.A. 73, 2206-2210

Powell, M. J. D. (1965) Comput.J. 7, 303-307

Powell, M. J. D. (1972) A.E.R.E. Rep. No. T.P. 492, A.E.R.E., Harwell

Sharrock, M. \& Yonetani, T. (1976) Biochim. Biophys. Acta 434, 333-344

Thomson, A. J., Brittain, T., Greenwood, C. \& Springall, J. P. (1976) FEBS Lett . 67, 94-98

Thomson, A. J., Brittain, T., Greenwood, C. \& Springall, J. P. (1977) Biochem. J. 165, 327-336

Van Gelder, B. F. (1963) Biochim. Biophys. Acta 73, 663665

Volpe, J. A., O'Toole, M. C. \& Caughey, W. S. (1975) Biochem. Biophys. Res. Commun. 62, 48-53

Wever, R., Van Drooge, J. H., Muijsers, A. O., Bakker, E. P. \& Van Gelder, B. F. (1977) Eur. J. Biochem. 73, 149-154

Yonetani, T. (1963) Enzymes 2nd Ed. 8, 41-79

Yoshikawa, S., Choc, M. G., O'Toole, M. C. \& Caughey, W. S. (1977) J. Biol. Chem. 252, 5498-5508

\section{APPENDIX I}

In order to see why models (1) and (2) behave differently it is necessary to solve analytically the set of simultaneous differential equations given in eqn. (7) of the main paper for the two sets of initial conditions. Such an analytical solution is only possible under pseudo-first order conditions such as exist in these experiments.

The solution of eqn. (7) (main paper) for model (1) is:

$$
\begin{aligned}
\mathrm{E}(t)= & E_{i}\left[\frac{k_{-1} k_{-2}}{\gamma_{1} \gamma_{2}}+\frac{\gamma_{1}^{2}-\gamma_{1}\left(k_{-1}+k_{-2}+k_{+2}\right)+k_{-1} k_{-2}}{\gamma_{1}\left(\gamma_{1}-\gamma_{2}\right)} \mathrm{e}^{-\gamma_{1} t}+\right. \\
& \left.\frac{\gamma_{2}^{2}-\gamma_{2}\left(k_{-1}+k_{-2}+k_{+2}\right)+k_{-1} k_{-2}}{\gamma_{2}\left(\gamma_{2}-\gamma_{1}\right)} \mathrm{e}^{-\gamma_{2} t}\right] \\
\mathrm{I}_{\mathrm{c}}(t)= & k_{\alpha} E_{i}\left[\frac{k_{-2}}{\gamma_{1} \gamma_{2}}+\frac{k_{-2}-\gamma_{1}}{\gamma_{1}\left(\gamma_{1}-\gamma_{2}\right)} \mathrm{e}^{-\gamma_{1} t}+\frac{k_{-2}-\gamma_{2}}{\gamma_{2}\left(\gamma_{2}-\gamma_{1}\right)} \mathrm{e}^{-\gamma_{2} t}\right] \\
\mathrm{II}_{\mathrm{c}}(t)= & k_{\alpha} k_{+2} E_{i}\left[\frac{1}{\gamma_{1} \gamma_{2}}+\frac{1}{\gamma_{1}\left(\gamma_{1}-\gamma_{2}\right)} \mathrm{e}^{-\gamma_{1} t}+\frac{1}{\gamma_{2}\left(\gamma_{2}-\gamma_{1}\right)} \mathrm{e}^{-\gamma_{2} t}\right] \\
\mathrm{E}(t)= & k_{-1} I_{\mathrm{c} i}\left[\frac{k_{-2}}{\gamma_{1} \gamma_{2}}+\frac{k_{-2}-\gamma_{1}}{\gamma_{1}\left(\gamma_{1}-\gamma_{2}\right)} \mathrm{e}^{-\gamma_{1} t}+\frac{k_{-2}-\gamma_{2}}{\gamma_{2}\left(\gamma_{2}-\gamma_{1}\right)} \mathrm{e}^{-\gamma_{2} t}\right] \\
\mathrm{I}_{\mathrm{c}}(t)= & I_{\mathrm{c} i[}\left[\frac{k_{\alpha}}{\gamma_{1} \gamma_{2}}+\frac{\gamma_{1}^{2}-\gamma_{1}\left(k_{\alpha}+k_{-2}\right)+k_{\alpha} k_{-2}}{\gamma_{1}\left(\gamma_{1}-\gamma_{2}\right)} \mathrm{e}^{-\gamma_{1} t}+\right. \\
& \left.\frac{\gamma_{2}^{2}-\gamma_{2}\left(k_{\alpha}+k_{-2}\right)+k_{\alpha} k_{-2}}{\gamma_{2}\left(\gamma_{2}-\gamma_{1}\right)} \mathrm{e}^{-\gamma_{2} t}\right] \\
\mathrm{II}_{\mathrm{c}}(t)= & k_{+2} I_{\mathrm{c} i}\left[\frac{k_{\alpha}}{\gamma_{1} \gamma_{2}}+\frac{k_{\alpha}-\gamma_{1}}{\gamma_{1}\left(\gamma_{1}-\gamma_{2}\right)} \mathrm{e}^{-\gamma_{1} t}+\frac{k_{\alpha}-\gamma_{2}}{\gamma_{2}\left(\gamma_{2}-\gamma_{1}\right)} \mathrm{e}^{-\gamma_{2} t}\right]
\end{aligned}
$$


where $E_{t}$ and $I_{\mathrm{c} t}$ are the concentrations of $\mathrm{E}$ and species $I_{\mathrm{c}}$ at $t=0 \mathrm{~s}$ in models (1) and (2) respectively; $\gamma_{1}$ and $\gamma_{2}$ (the observed rate constants for the fast and slow phases respectively) are roots of the quadratic equation:

$$
\begin{aligned}
& \gamma_{2}+\left(k_{\alpha}+k_{+2}+k_{-1}+k_{-2}\right)+k_{\alpha}\left(k_{+2}+k_{-2}\right)+ \\
& k_{-1} k_{-2}=0
\end{aligned}
$$

taken with reverse signs; and $k_{\alpha}$ is given by:

$$
k_{\alpha}=k_{+1}\left[\mathrm{CO}_{\mathrm{p}}\right]
$$

From eqns. (1) and (2) it is seen that the two exponentials, $\theta_{1}$ and $\theta_{2}$, making up a $\log$-linear plot will be in the form:

$$
\begin{aligned}
& \log \left(\theta_{1}\right)=\log \left[\frac{\varepsilon_{j} a_{1}+\varepsilon_{k} b_{1}}{c}\right]-\frac{\gamma_{1} t}{2.303} \\
& \log \left(\theta_{2}\right)=\log \left[\frac{\varepsilon_{j} a_{2}+\varepsilon_{k} b_{2}}{c}\right]-\frac{\gamma_{2} t}{2.303}
\end{aligned}
$$

\section{APPENDIX II}

We summarize the equations used to calculate the S.D. of the various parameters calculated from the rate constants at $188 \mathrm{~K}, k_{i}\left(T_{\mathrm{D}}\right)$, and the energies of activation, $E_{\mathrm{A} i}{ }^{0}$, in terms of the S.D. $1 \mathrm{n}$ of the optimized parameters [given in Tables 4 and 5 (main paper) for models (1) and (2) respectively] and the correlation matrix [Tables 2 and 3 (main paper) for models (1) and (2) respectively]. In these calculations, the error on the temperature estimation is ignored as this was less than $\pm 0.05 \mathrm{~K}$.

$T_{\mathrm{D}}$ refers to the reference temperature, $188 \mathrm{~K}$; the variance of the natural logarithm of a given optimized parameter, $\operatorname{var}(\ln x)$, is simply the square of the S.D. ${ }_{\text {In }}$ of the parameter, [S.D. $\left.\left.\ln x\right)\right]^{2}$; and $r\left(x_{j}, y_{j}\right)$ is the correlation coefficient relating $x_{j}$ to $y_{j}$.

The S.D.1n of a given rate constant, $k_{i}$, at a temperature $T_{j}$ is given by:

$$
\begin{aligned}
\text { S.D. }\left[\ln k_{l}\left(T_{j}\right)\right]=\left[\operatorname{var}\left[\ln k_{i}\left(T_{\mathrm{D}}\right)\right]+\left(\frac{1}{T_{\mathrm{D}}}-\frac{1}{T_{J}}\right)^{2} \frac{E_{\mathrm{A} i}^{02}}{R^{2}} \operatorname{var}\left(\ln E_{\mathrm{A} i}\right)+\right. \\
\left.+\left(\frac{1}{T_{\mathrm{D}}}-\frac{1}{T_{J}}\right) \frac{2 r\left[k_{l}\left(T_{\mathrm{D}}\right), E_{\mathrm{A}}^{0}\right] E_{\mathrm{A} i}^{0} \text { S.D. }\left[\ln k_{i}\left(T_{\mathrm{D}}\right)\right] \text { S.D. }\left(\ln E_{\mathrm{A} i}\right)}{R}\right]^{\frac{1}{2}}
\end{aligned}
$$

with slopes $-\gamma_{1} / 2.303$ and $-\gamma_{2} / 2.303$ respectively; $a_{1}, a_{2}, b_{1}, b_{2}$ and $c$ are constants (which are functions of $\gamma_{1}, \gamma_{2}$ and the rate constants); $\varepsilon_{j}$ and $\varepsilon_{k}$ are the extinction coefficients of the two species, $j$ and $k$, being monitored. Denoting the two intercepts on the $\log (\theta)$ axis by $\beta_{1}$ and $\beta_{2}$, it is readily seen that when $\varepsilon_{j}=\varepsilon_{k}, \beta_{1}-\beta_{2}$ will be at a maximum; when either $\varepsilon_{j}=0$ or $\varepsilon_{k}=0, \beta_{1}-\beta_{2}$ will be at a minimum. When $\beta_{1}-\beta_{2}$ is greater than 1.8 , the biphasic nature of such a $\log$-linear plot may be obscured even if the ratio $\gamma_{2} / \gamma_{1}$ is in the range $1-5$.
The S.D. of $\Delta H_{i}^{*}\left(T_{j}\right)$ is given by:

$$
\text { S.D. }\left[\Delta H_{i}^{\ddagger}\left(T_{j}\right)\right]=\text { S.D. }\left(\ln E_{\mathrm{A} i}^{0}\right) E_{\mathrm{A} i}^{0}
$$

(i.e. the S.D. of $\Delta H_{i}^{*}$ is temperature-independent). The s.D. of $\Delta G_{i}^{*}\left(T_{j}\right)$ is given by:

$$
\text { S.D. }\left[\Delta G_{i}^{\ddagger}\left(T_{j}\right)\right]=-R T_{j} \text { S.D. }\left[\ln k_{i}\left(T_{j}\right)\right]
$$

where S.D. $\left[\ln k_{t}\left(T_{j}\right)\right]$ is given by eqn. (1).

The S.D. of $\Delta S_{i}^{*}\left(T_{j}\right)$ is given by:

$$
\begin{aligned}
\text { S.D. }\left[\Delta S_{i}^{\ddagger}\left(T_{j}\right)\right]=\left[R^{2} \operatorname{var}\left[\ln k_{i}\left(T_{j}\right)\right]+\frac{E_{\mathrm{A} i}^{02}}{T_{i}{ }^{2}} \operatorname{var}\left(\ln E_{\mathrm{A} i}^{0}\right)+\right. \\
\left.+\frac{2 r\left[k_{i}\left(T_{\mathrm{D}}\right), E_{\mathrm{A} i}^{0}\right] E_{\mathrm{A} i}^{0} \text { S.D. }\left[\ln k_{i}\left(T_{j}\right)\right] \text { S.D. }\left(\ln E_{\mathrm{A} i}^{0}\right) R}{T_{J}}\right]
\end{aligned}
$$

